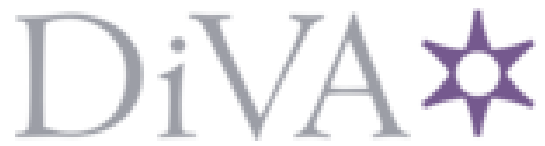

http://www.diva-portal.org

Preprint

This is the submitted version of a paper published in Carbon.

Citation for the original published paper (version of record):

Sun, J., Morales-Lara, F., Klechikov, A., Talyzin, A V., Baburin, I A. et al. (2017)

Porous graphite oxide pillared with tetrapod-shaped molecules

Carbon, 120: 145-156

https://doi.org/10.1016/j.carbon.2017.05.007

Access to the published version may require subscription.

N.B. When citing this work, cite the original published paper.

Permanent link to this version:

http://urn.kb.se/resolve?urn=urn:nbn:se:umu:diva-137608 


\title{
Porous graphite oxide pillared with tetrapod-shaped molecules
}

Jinhua Sun ${ }^{\mathrm{a}}$, Francisco Morales-Lara ${ }^{\mathrm{b}, \mathrm{c}}$, Alexey Klechikov ${ }^{\mathrm{a}}$, Alexandr V. Talyzin ${ }^{\mathrm{a} *}$, Igor A. Baburin $^{\mathrm{d}}$, Gotthard Seifert ${ }^{\mathrm{d}}$, Francesca Cardano ${ }^{\mathrm{b}}$, Michele Baldrighi ${ }^{\mathrm{b}}$, Marco Frasconi ${ }^{\mathrm{e}}{ }^{\mathrm{e}}$, and Silvia Giordani ${ }^{\mathrm{b}, \mathrm{c}, \mathrm{f}, *}$.

${ }^{\mathrm{a}}$ Umeå University, Department of Physics, S-90187 Umeå, Sweden.

${ }^{\mathrm{b}}$ Istituto Italiano di Tecnologia (IIT), Nano Carbon Materials, Via Morego 30, Genoa, Italy.

${ }^{\mathrm{c}}$ Istituto Italiano di Tecnologia (IIT), Graphene Labs, Via Morego 30, Genoa, Italy.

d Technische Universität Dresden, Theoretische Chemie, Bergstraße 66b, 01062 Dresden, Germany.

${ }^{\mathrm{e}}$ University of Padova, Department of Chemical Sciences, Via Marzolo 1, Padova, Italy.

${ }^{\mathrm{f}}$ University of Turin, Department of Chemistry, Via Giuria 7, Turin, Italy.

\begin{abstract}
Porous pillared graphene oxide $(\mathrm{GO})$ materials were prepared using solvothermal reaction of Hummers GO with solution of Tetrakis(4-aminophenyl)methane (TKAm) in methanol. The intercalation of TKAm molecules between GO sheets performed under swelling condition results in expansion of inter-layer distance of GO from $\sim 7.5 \AA$ to $13-14 \AA$. Pillaring GO with 3D shaped TKAm molecules could be an advantage for the preparation of stable pillared structures compared to aliphatic or aromatic diamines. Insertion of TKAm molecules into inter-layer space of GO results in formation of interconnected network of sub-nanometer slit pores. The expanded GO structure prepared with optimized GO/TKAm composition shows Specific Surface Area
\end{abstract}

\footnotetext{
*Corresponding authors: alexandr.talyzin@physics.umu.se (Alexandr Talyzin), marco.frasconi@unipd.it (Marco Frasconi), silvia.giordani@iit.it (Silvia Giordani).
} 
(SSA) up to $660 \mathrm{~m}^{2} / \mathrm{g}$ which is among the highest reported for GO materials pillared using organic spacers. Modeling of GO/TKAm structures shows that maximal SSA of about 2300 $\mathrm{m}^{2} / \mathrm{g}$ is theoretically possible for realistic concentration of pillaring molecules in GO interlayers. Hydrogen sorption by GO/TKAm is found to follow standard correlation with SSA with highest uptakes of $1.66 \mathrm{wt} \%$ achieved at $77 \mathrm{~K}$ and $0.25 \mathrm{wt} \%$ at $295 \mathrm{~K}$. Theoretical simulations show that pillared GO structures do not provide improvement of hydrogen storage beyond well-established physisorption trends even for idealized materials with subnanometer pores and SSA of 2300$3700 \mathrm{~m}^{2} / \mathrm{g}$

\section{Introduction.}

The unique properties of graphene oxide (GO) multilayers are promising for variety of applications, e.g. for preparation of mechanically strong papers [1], membranes for gas and liquid mixtures separation [2-8], nano-filtration [9, 10], water desalination [11, 12], etc. The hydrophilic nature of GO was reported in very early studies [13, 14], and by the 60-s it was already well known that GO swells in polar solvents with expansion of the interlayer distance from 6-7 $\mathrm{A}$ up to $40-50 \AA$ depending on the molecular size and amount of intercalated solvent [2, 15, 16]. Swelling enables penetration of various molecules into inter-layer space of GO. The stronger is expansion of GO lattice due to swelling, the larger molecules can be inserted and used as "pillars" for preparation of porous structures. Perhaps the most studied GO solvates by now are those with alcohols [17]. It is known that GO prepared by Hummers method [18] (H-GO) exhibits much stronger expansion of lattice due to swelling compared to GO prepared by Brodie method (B-GO) [13] while B-GO shows better ordered structures with well-defined layer by layer intercalation of solvents [8, 19-22]. Graphite and graphene oxides provide enormous possibilities for chemical modification with the aim to prepare materials with porous structures using pillaring molecules [23-26]. Pillared GO materials (PGO) with high surface area could be useful for many possible applications, e.g. gas storage [24], materials for supercapacitors [27] and membranes [28]. PGO's have been considered also as a promising material for hydrogen storage applications thanks to theoretical predictions of improved gravimetric sorption in subnanometer slit pores formed by graphene planes [29]. Graphite shows $\sim 3.35 \AA$ spacing between graphene sheets. According to theoretical studies the optimal separation of graphene sheets for 
maximal hydrogen sorption is predicted to be on the level of 7-12 $\AA$ [29, 30]. However, these theoretical simulations simply postulated variations of inter-layer distance while experimental realization requires some pillaring molecules which could hold the graphene sheets separated from each other.

Several approaches have been proposed over the past decade to make pillared graphenerelated materials, including functionalization of dispersed reduced GO (r-GO), pyrolysis of intercalated GO [31-33] or pillaring with various relatively large nanoparticles. For example, pillaring with carbon black particles resulted in preparation of materials with relatively high SSA of up to $\sim 1000 \mathrm{~m}^{2} / \mathrm{g}$. [34] The variability of diameter and shape of those nanoparticles has not allowed, however, to prepare ordered structure with precise size of pores . In contrast, our study is focused (i) on using molecular pillars, which have a definite shape and size, and (ii) preparation procedure, which do not include dispersion of graphite oxide on single layered graphene oxide sheets. Graphene oxide seems to be the best available precursor for the preparation of pillared materials since it can be chemically functionalized with pillaring molecules. These molecules can be inserted by swelling the GO in polar solvents resulting in the expansion of inter-layer distance of GO. It is important to emphasize that the expansion of GO inter-layer distance is dependent on the solvent used as well as on the also on temperature and pressure conditions and it is significantly different for graphite oxides prepared using e.g. Brodie or Hummers methods [17, 18, 29-31]. This concept was tested in several studies which include e.g. solvothermal reaction of graphite oxide powder with 1,4-benzene diboronic acid (DBA). An idealized structural model where DBA molecules link neighboring graphene sheets was proposed for these materials. [23] Later studies demonstrated that these molecular linkers are likely to attach only on one side of inter-layer. [24, 35] Several other linker molecules or nanoparticles have also been tested for preparation of PGO [25, 28, 36]. The experimental SSA reported for some of these PGO materials $\left(\sim 400-800 \mathrm{~m}^{2} / \mathrm{g}\right)$ is significantly higher compared to pristine graphite oxide. Our earlier experiments also confirmed the formation of porous GO/DBA structures with SSA values up to $1000 \mathrm{~m}^{2} / \mathrm{g}$ and sub-nanometer pore width [24]. However, PGO materials with SSA on that level are not competitive for hydrogen storage applications. The best values of SSA for activated graphene materials are over $3000 \mathrm{~m}^{2} / \mathrm{g}$ [37] and several structures with SSA above $6000 \mathrm{~m}^{2} / \mathrm{g}$ are reported for Metal Organic Framework (MOF) materials [38]. New pillared GO and pillared graphene materials with higher SSA values must be prepared if 
they are to be promising for hydrogen storage applications. Therefore, there is strong interest to test new pillaring molecules for preparation of porous GO materials with high SSA.

Aliphatic and aromatic amines are promising types of molecules that have been previously tested for the preparation of PGO $[15,16,39,40]$. The interlayer distance of GO intercalated with linear aliphatic amines has been reported to increase linearly from $\sim 22 \AA$ to $\sim 60 \AA$ according to the size of the molecule's (4-20 carbon atoms) [15]. For example, the reaction of pentylamine with GO at $40-50^{\circ} \mathrm{C}$ studied by A.Lerf et al resulted in GO interlayer distance of $19.6 \AA$ in asprepared sample and $13.6 \AA$ for the washed and dried sample [41]. The insertion of pentylamine molecules into GO structure has been reported in this study mostly by intercalation and only partly by nucleophilic attack on epoxy groups of GO. On the other hand, reaction of long chain alkylamines at near ambient temperature was reported to result in three different types of intercalated species: hydrogen-bonded neutral amines, hydrogen-bonded protonated amines and protonated amines with ionic interaction to GO.[42] The intercalated amines can be removed by washing with ethanol.

The first attempt to prepare PGO or pillared graphene using prolonged ambient temperature reaction with several amines followed by reduction resulted in expanded (relative to precursor GO) interlayer distance of $11.3 \AA$. However, there was no increase of surface area measured by nitrogen sorption $\left(<2 \mathrm{~m}^{2} / \mathrm{g}\right)$ [39]. It was suggested that the main reaction pathway was nucleophilic addition on the epoxy groups with covalent attachment of the pillaring molecules to GO.

In recent years several attempts to prepare PGO using diamines have been performed, e.g. by reactions of GO with ethylenediamine, butylenediamine, and p-phenylenediamine which resulted in expansion of the GO lattice $(9.1 \AA, 9.7 \AA$ and $10.1 \AA$ respectively) but surface area of these materials was not evaluated [28]. Several other studies reported reactions of amines or diamines with GO but not SSA or gas sorption properties of prepared materials [36, 43, 44]. The lattice expansion, however, does not imply that diamine molecules inter-link GO planes or that a pillared porous structure is formed. Moreover, it can be expected that a pillared GO structures based on diamine linkers with linear shape would be unstable even against the slight shear stress. The highest SSA so far achieved for diamine-functionalized GO is $276 \mathrm{~m}^{2} / \mathrm{g}$ which is a relatively small increase relative to the precursor GO used in these experiments $\left(200 \mathrm{~m}^{2} / \mathrm{g}\right)$ [35]. One of 
the possible reasons for the relatively small SSA values achieved so far using linear shaped amines as pillaring molecules could be the low stability of the material against shear stress which results in the collapse of pores.

Therefore, we propose here that rigid 3D shaped molecules are more likely to provide higher mechanical stability for porous pillared GO structures. To our knowledge the only amine molecule with 3D shape so far attempted for preparation of pillaring of GO is adamantylamine but the reported SSA value of this material is only $37 \mathrm{~m}^{2} / \mathrm{g}$, comparable to that of dispersed and freeze dried GO [45].

In this study we report novel pillared GO material prepared using solvothermal reaction with Tetrakis(4-aminophenyl)methane (TKAm). The molecule has four amine groups which makes inter-linking of GO planes more likely and a 3D shape which could be of advantage for stability of pillared structures. Optimization of synthesis conditions resulted in preparation of materials with SSA values over $600 \mathrm{~m}^{2} / \mathrm{g}$ and interlayer distance of $\sim 14 \AA$ which are compatible with structural model of GO sheets interconnected by TKAm pillars. Hydrogen sorption evaluated for GO/TKAm at $77 \mathrm{~K}$ and ambient temperature showed correlation with observed SSA according to standard trends known for physisorption on high surface area materials.

\section{Experimental}

\subsection{Materials}

The precursor "pillaring" compound TKAm was prepared according to previously reported literature procedures with minor modifications [46], see supplementary data for details.

Commercial graphite by Alfa Aesar (natural powder, 200 mesh, $99.9999 \%$ ) was used as starting material for the preparation of graphite oxide samples following the Hummers method [18]. Characterization by XRD, FTIR, TGA and XPS confirmed high quality of samples and absence of unreacted graphite impurities. A $\mathrm{C} / \mathrm{O}=2.5$ composition was determined by XPS. HGO samples always show some traces of sulfur contamination but careful washing allowed to reduce $\mathrm{S}$ content to $0.3 \%$. A Brodie graphite oxide (B-GO) sample was synthesized using a graphite sample provided by Graphexel Ltd. (natural fine flake, 0-200 $\mu \mathrm{m},>99.5 \%$. Two 
oxidative treatments [47] have been successively applied to obtain the B-GO sample with $\mathrm{C} / \mathrm{O}=2.55$.

\subsection{Synthesis of GO/TKAm}

GO/TKAm samples were prepared by a solvothermal synthesis method [24] using the assynthesized GO powder. Precursor GO powder (typically $50 \mathrm{mg}$ ) and TKAm were mixed in various weight ratios in a stainless steel reactor and methanol $(10 \mathrm{~mL})$ was added. For hydrogen sorption experiments larger samples with initial weight of GO powder of 100 or $200 \mathrm{mg}$ and optimal load of TKAm were prepared. The reactor was closed under nitrogen and annealed at 90 ${ }^{\circ} \mathrm{C}-130{ }^{\circ} \mathrm{C}$ for $24 \mathrm{~h}$. The reaction mixture was centrifuged (4400 rpm for $15 \mathrm{~min}$ ) in order to separate the powder from the remaining methanol solution. The unreacted or simply intercalated TKAm molecules were removed by repeated washing with methanol following a reported procedure [42]. The sample was finally dried under vacuum at room temperature for at least $12 \mathrm{~h}$.

The properties of graphite oxide depend very strongly on synthesis method [18]. Two types of GO were tested for reaction with TKAm in our experiments: GO made by Brodie method [19] and GO made by Hummers method [20]. However, attempts to make reaction of B-GO with TKAm were not successful, suggesting the smaller swelling of B-GO in methanol $(\mathrm{d}(001) \sim 10 \AA)$ compared to $\mathrm{H}-\mathrm{GO}(\mathrm{d}(001) \sim 13 \AA)$ at ambient conditions [48].

The as-synthesized GO/TKAm samples were characterized by thermogravimetric analysis (TGA), nitrogen sorption, X-ray diffraction (XRD), X-ray photoelectron (XPS), Fourier Transform Infrared (FTIR) and Raman spectroscopies. TGA was done by using a Mettler Toledo TGA/DSC1 STARe System. Experiments were performed from room temperature up to $700{ }^{\circ} \mathrm{C}$ at a heating rate of $5{ }^{\circ} \mathrm{C} / \mathrm{min}$ under nitrogen flow $(50 \mathrm{~mL} / \mathrm{min})$.

\subsection{Characterization}

The nitrogen sorption isotherms were measured using a Quantachrome Nova 1200e Surface area $\&$ Pore size analyzer at liquid nitrogen temperature. Samples were degassed under vacuum at $110^{\circ} \mathrm{C}-120{ }^{\circ} \mathrm{C}$ for at least $12 \mathrm{~h}$. The relative pressure range for the calculation of (BET) specific surface area was determined by plotting the adsorption isotherm as $\mathrm{V}\left(1-\mathrm{P} / \mathrm{P}_{0}\right)=\mathrm{f}\left(\mathrm{P} / \mathrm{P}_{0}\right)$. The selected relative pressure range should correspond to the part where $\mathrm{V}\left(1-\mathrm{P} / \mathrm{P}_{0}\right)$ continuously 
increases with $\mathrm{P} / \mathrm{P}_{0}$ [49]. A slit pore QSDFT equilibrium model was applied to evaluate the cumulative surface area, pore volume and pore size distribution. The error in BET SSA values is about $\sim 1-1.5 \%$ depending on size of samples.

Panalytical X'pert X-ray diffractometer with $\mathrm{Cu}-\mathrm{K} \alpha$ radiation $(\lambda=1.5418 \AA)$ was used to record the diffraction patterns. XPS spectra were recorded with a Kratos Axis Ultra electron spectrometer equipped with a delay line detector. A monochromated Al K- $\alpha$ source operated at $150 \mathrm{~W}$, a hybrid lens system with a magnetic lens, providing an analysis area of $0.3 \times 0.7 \mathrm{~mm}$, and a charge neutralizer were used for the measurements. The binding energy scale was adjusted with respect to the $\mathrm{C} 1 \mathrm{~s}$ line of aliphatic carbon, set at $285.0 \mathrm{eV}$. All spectra were processed with the Kratos software. FTIR spectra were collected using a Bruker IFS 66v/S in diffuse reflectance mode. Raman spectra were recorded by using a Renishaw spectrometer equipped with a $633 \mathrm{~nm}$ and $785 \mathrm{~nm}$ lasers.

\subsection{Hydrogen adsorption measurements}

Hydrogen adsorption was measured at room temperature using a Rubotherm gravimetric system, see details elsewhere [50]. Isotherms were recorded under $\mathrm{H}_{2}$ pressures up to 120 bar with typical sample size of 100-200 mg. Degassing of samples prior to $\mathrm{H}_{2}$ tests was usually performed at high vacuum conditions at $120^{\circ} \mathrm{C}$ for $12-16 \mathrm{~h}$. On every step of the hydrogen adsorption isotherm temperature and pressure were stabilized for $\sim 15$ min using a circulation liquid thermostat. The precision in measured uptake values is estimated to be $\pm 0.02 \mathrm{wt} \%$ based on instrumental errors of weight and temperature sensors. FLUIDCAL software was used for the calculations of fluid density of hydrogen and helium. Detailed analysis of error sources and methods of their accounting for similar gravimetric system can be found elsewhere [51]. The $\mathrm{H}_{2}$ adsorption tests were also performed using a Hiden Isochema Intelligent Manometric Instrument (IMI) [52],[53] volumetric system at ambient temperatures and at $77 \mathrm{~K}$ (liquid nitrogen immersion cell).

Hydrogen adsorption isotherms were calculated based on Grand canonical Monte Carlo simulations in the same way as done in our former paper.[54] Structural models of adsorbents were built up so as to respect stereochemically reasonable distances and subsequently optimized 
using density-functional-based tight-binding method [55] as implemented in the DFTB+ package (http://www.dftb-plus.info).

\section{Results and discussion}

\subsection{Structure and composition of GO/TKAm materials}

The main aim of this study was to create PGO materials with high surface area using TKAm molecules as molecular pillars and to verify hydrogen sorption properties of these materials. Therefore, we define here the term "pillared" only for material which has interconnected pore network accessible for penetration and sorption of gases. The "pillared" structure is distinguished here from intercalated (expanded) GO structure which is in general not porous if the density of pillars is high or continuous layer of molecules is formed. For example, even the precursor graphite oxide has inter-layer distance of $\sim 7.5 \AA$ and could be hypothetically considered as a graphene "pillared" by oxygen functionalities with $\sim 3 \AA$ pore size sufficient for gas penetration [56]. However, no porous network is found in GO materials due to high density of functional groups while the SSA measured even from finely dispersed and freeze dried samples is typically below $100 \mathrm{~m}^{2} / \mathrm{g}$. Therefore, precursor GO cannot be considered as a pillared material and chemical modification is required to create porous structure.

Fig. 1 shows Tetrakis(4-aminophenyl)methane (TKAm) which is the molecule selected as a possible pillar for preparation of expanded GO structure and the suggested reaction pathway explored for the synthesis of nanoporous material. 

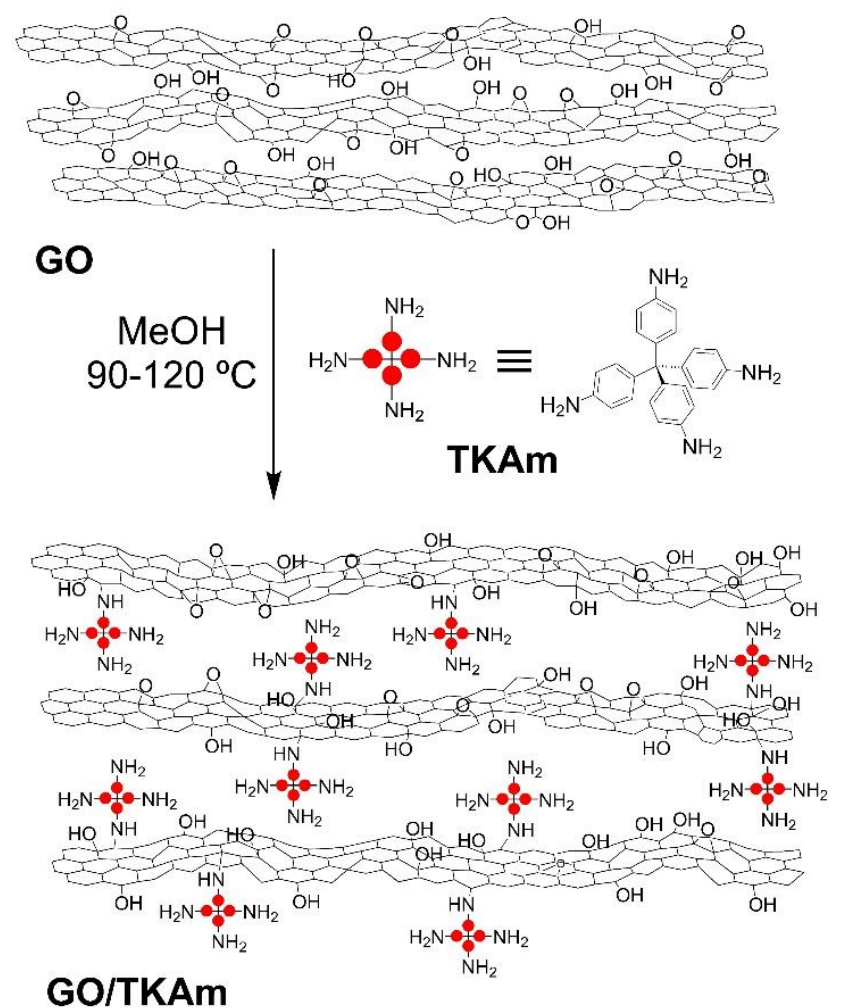

Fig. 1. Tetrakis(4-aminophenyl)methane (TKAm) molecule and reaction pathway for preparation of pillared structure.

The TKAm molecule is one of commonly used building blocks for the synthesis of Covalent Organic Framework (COF) materials [57, 58]. Due to the presence of a tetrahedral central carbon atom and the steric hindrance among the phenyl rings, the molecule assumes a permanent 3D shape which allows to always expose towards each GO layer at least one amino functional group that can be used to covalently attach the molecule to the carbon layer. Moreover, the non-planar geometry of TKAm could be advantageous for the creation of stable pillars.

The synthesis of pillared GO presented here involves three steps:

1) Swelling (expansion) of GO structure in solution of pillared molecules.

2) Insertion and attachment of pillaring molecules into GO inter-layers at elevated temperature conditions 
3) Removing solvent by evaporation while the pillaring molecules keep the GO lattice in expanded state thus creating porous structure

Note that dispersion of graphite oxide is intentionally avoided in this procedure which is very similar to earlier studied synthesis of DBA-PGO [23, 24, 35].

Fig. 2 shows three possible types of GO/TKAm structures with high surface area simulated using theoretical modelling: schematic structure of GO pillared with TKAm (a) with emore detailed view of non-covalent intercalation of TKAm molecules (b), covalent attachment of TKAm molecules to GO sheets trough two of the four amine groups (c) and only one amino group reacted with GO thus attaching the molecule only to one side while the other side is noncovalent (d). It is clear that other kinds of structures are also possible, even if less likely, such as a structure where all the four amino groups reacted with GO. Using realistic lateral distances between TKAm molecules of $15 \AA$ and $7 \AA$ (which correspond to composition in weight ratios GO:TKAm 1:0.11 and 1:0.22) the maximal theoretical SSA of simulated structures was estimated to be $2000 \mathrm{~m}^{2} / \mathrm{g}$ and $2230 \mathrm{~m}^{2} / \mathrm{g}$ respectively. The expected inter-layer distance for covalently pillared structure shown in Fig. 2 is $\sim 14 \AA$ and for non-covalent $\sim 15 \AA$.

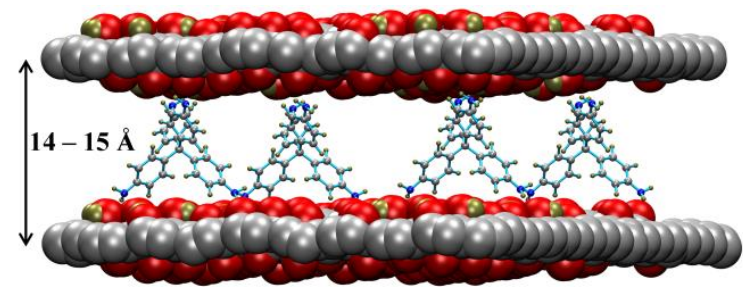

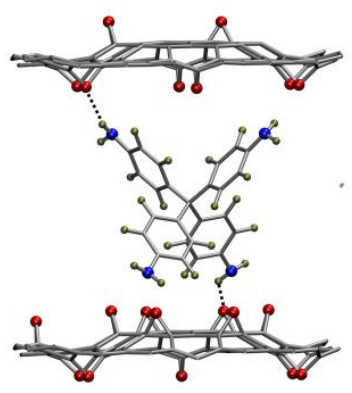

$b$

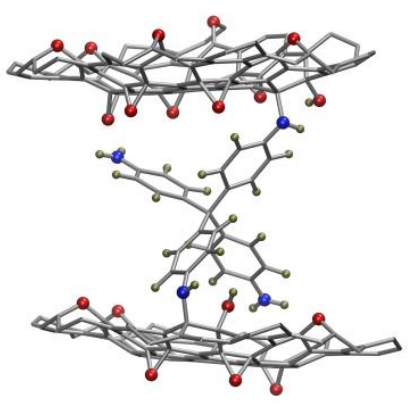

c

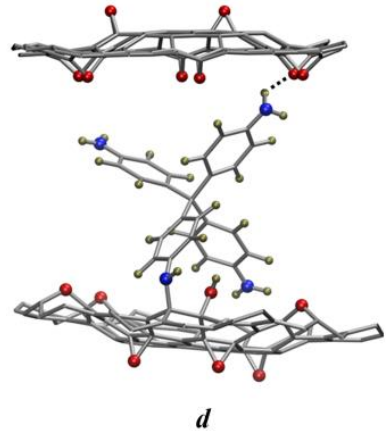

d

Fig. 2. A model of the GO/TKam structure (a). Possible interactions cross-linking the layers are indicated: hydrogen bonds (dotted lines in b), covalent bonds on both sides GO interlayer (c) and with the TKAm molecule covalently attached only to one side while the other side is noncovalently bound to GO. Carbon atoms are gray, nitrogens are blue, oxygens are red. 
Assuming the thickness of GO layer of $7 \AA$ the structure shown in Fig. 2 provides pores with size of $8 \AA$, sufficient for hydrogen molecule penetration.

Preliminary tests showed that TKAm molecules are easily intercalated into HGO structure using methanol solution at ambient temperature as revealed by XRD. Precursor HGO shows $\mathrm{d}(001)=7.9 \AA$. Immersion of HGO powder in TKAm solution (in excess amounts) results in expansion of the $00 \ell$ - lattice parameter up to $15.88 \AA$ due to swelling but the change is not completely reversible. The $\mathrm{d}(001)=13.5 \AA$ is found after air drying of the sample and $\mathrm{d}(001)=13.1 \AA$ after vacuum drying. This result is in agreement with earlier studies of amines intercalation into GO structure [41]. Most of the intercalated TKAm molecules can be removed by careful washing the sample with methanol as observed by XRD $(\mathrm{d}(001)=8.7 \AA$ after washing) but pristine GO with $\mathrm{d}(001)=7.9 \AA$ was not recovered even after vacuum drying of the sample. The ambient temperature intercalation of TKAm is likely to be non-covalent and the molecules form continuous layer with no pore network. It is interesting that Brodie GO could not be intercalated with TKAm, most likely due to smaller swelling in methanol $\mathrm{d}(001)=9.8 \AA$ compared to required $\sim 15 \AA$ for pillared structure (see Fig. 2) which makes insertion of TKAm molecules into GO interlayers impossible.

However, we were able to prepare effective porous pillared of GO/TKAm material using methanol solution of TKAm and conditions of solvothermal reaction similar to those tested previously for GO reaction with DBA molecules [24]. Most important parameters optimized here for this solvothermal reaction are temperature and initial ratio of GO: TKAm. The temperature of reaction is limited by the degradation of $\mathrm{GO}$ due to loss of oxygen containing functional groups which starts at $\sim 140^{\circ} \mathrm{C}$. Our experiments demonstrated that maximal SSA can be achieved using HGO: TKAm ratios of about 0.3-0.5. The temperature of reaction within 90$130^{\circ} \mathrm{C}$ interval provides samples with similar maximal SSA values of $\sim 620-660 \mathrm{~m}^{2} / \mathrm{g}$, Fig. 3,4 Maximal value of SSA achieved for HGO/TKAm samples was $660 \mathrm{~m}^{2} / \mathrm{g}$ for temperature of reaction $110^{\circ} \mathrm{C}$. The values of surface area are also affected by conditions of sample washing (to remove unreacted products) and guest methanol molecules removal by vacuum degassing. 

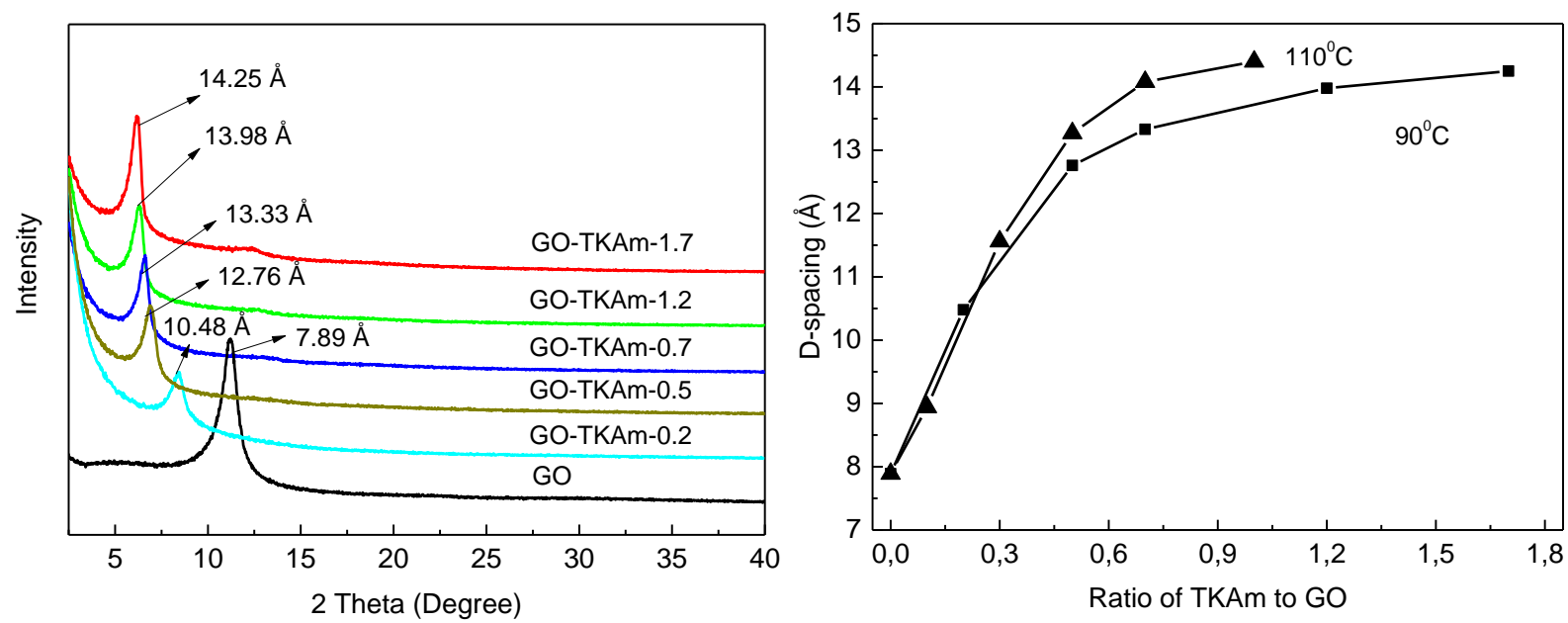

Fig. 3. Expansion of GO lattice due to intercalation of TKAm after solvothermal reaction preformed in methanol: a) XRD patterns recorded for samples after reaction at $90^{\circ} \mathrm{C}$ for 24 hours with variation of loading GO: TKAm weight ratio ; b) inter-layer distance of GO/TKam for two sets of samples synthesized at $90^{\circ} \mathrm{C}$ and $110^{\circ} \mathrm{C}$. XRD patterns were recorded under conditions of dynamic vacuum.

XRD data recorded from GO/TKAm samples demonstrate that interlayer distance of GO/TKAm saturates at 14.2-14.4 $\AA$ and do not increase further if composition of GO:TKAm is increased over $\sim 0.6-0.7$. However, the highest SSA values are observed for samples with $\mathrm{d}(001)$ in the range $10.5 \AA-13.5 \AA$. The results shown in Fig. 3 are in agreement with formation of pillared structures provided by theoretical modelling. The inter-layer distance of $13-14.4 \AA$ found experimentally is somewhat lower compared to the models, while the SSA values are smaller compared to theoretically possible maximum of over $2000 \mathrm{~m}^{2} / \mathrm{g}$. Most likely, the difference compared to ideal structure could be explained by the inhomogeneous structure/oxidation of GO itself which results in incomplete intercalation of some GO interlayers. Some of the inter-layers may not be expanded sufficiently to provide contribution to the surface area. The random stacking of layers with some variation in inter-layer distance will be detected by XRD as decreased averaged lattice parameter due to effects of interstratification and intrastratification $[21,59]$.

Some of the GO/TKAm samples were also tested for swelling properties. Vacuum dried sample with $\mathrm{d}(001)=13.0 \AA$ was immersed in excess of water and ethanol which resulted in lattice expansion up to $15.7 \AA$ and $16.2 \AA$ respectively. The increase of inter-layer distance corresponds 
approximately to the insertion of one layer of water or ethanol but does not exceed significantly the value of $\sim 14 \AA$ for the simulated structures. Therefore, we tested swelling using larger 1 octanol molecules and in this case the maximal swelling up to $\mathrm{d}(001)=17.3 \AA$ was observed. The change by $4 \AA$ cannot be anymore explained by filling pores of the pillared GO/TKAm structure and some change in orientation of TKAm molecules. Therefore, one-side attachment of TKAm on GO seems to be most likely considering results of swelling experiments.

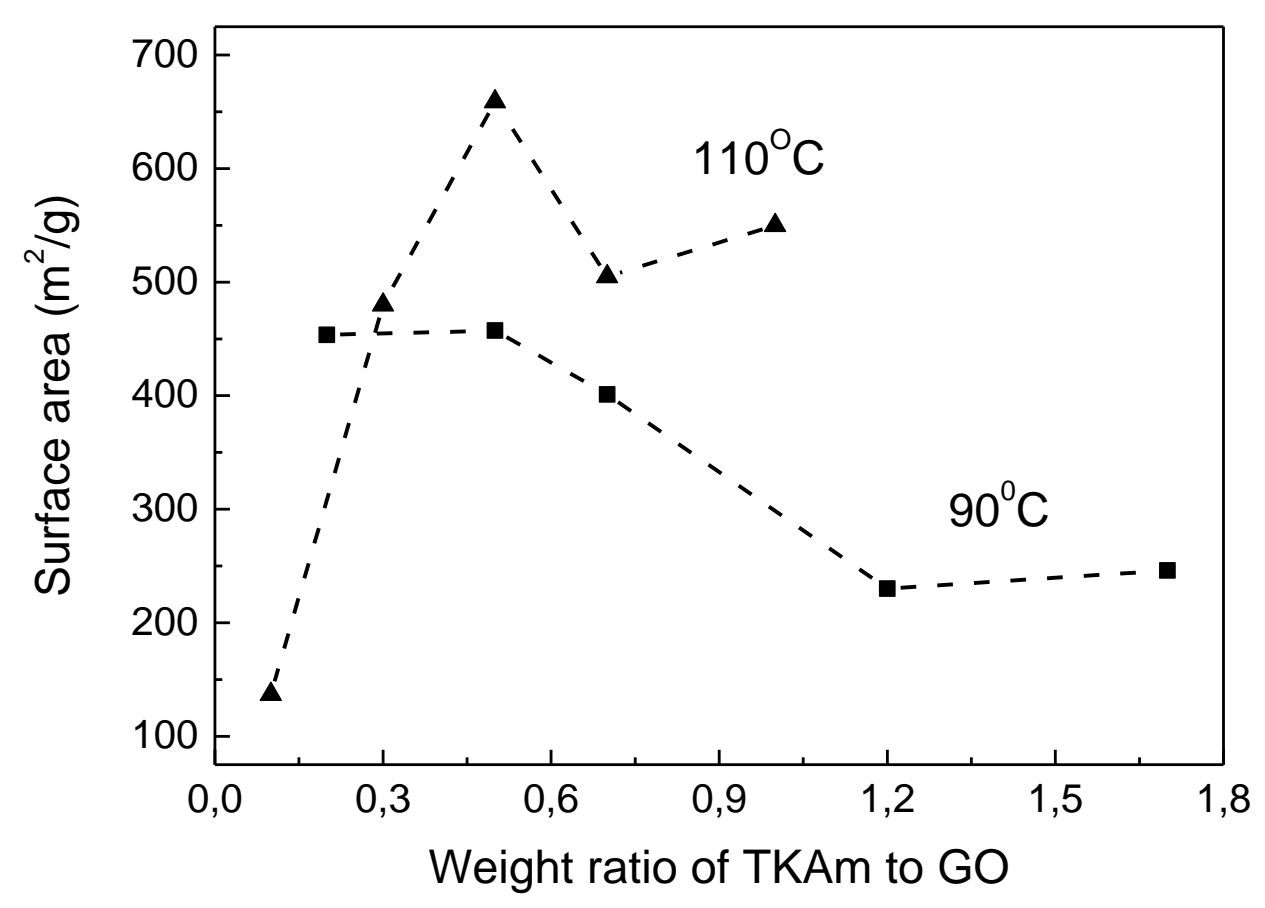

Fig. 4. SSA for two sets of GO/TKAm samples prepared with variation of initial GO:TKAm weight ratio at $110^{\circ} \mathrm{C}(\boldsymbol{\Delta})$ and $90^{\circ} \mathrm{C}(\mathbf{\square})$.

In agreement with expected trends, too high load of TKAm molecules in the reaction mixture results in a decrease of SSA values due to excessive density of pillaring molecules intercalated into the structure. However, the exact composition and structure of synthesized GO/TKAm samples cannot be extracted from XRD data. Microscopy also does not provide additional information about the structure of PGO except that the shape of grains remains similar to precursor graphite oxide keeping original shape with grains of several hundred nm thickness (see Fig. 5 for SEM images and Figure 3S in SI) Disordered structures are typical for GO-based 
materials and some other characterization methods are required to establish their structure and type of attachment for pillaring molecule to GO sheets. Additional evidence of TKAm intercalation was obtained using FTIR and Raman spectroscopy (Fig. 1S and 2S in SD). The main peaks of TKAm revealed in reference spectra of precursor powder were also observed in the spectra of materials prepared by solvothermal reaction with GO. The change in relative intensity and broadening several peaks can be attributed to chemical modification of TKAm inserted into GO structure.

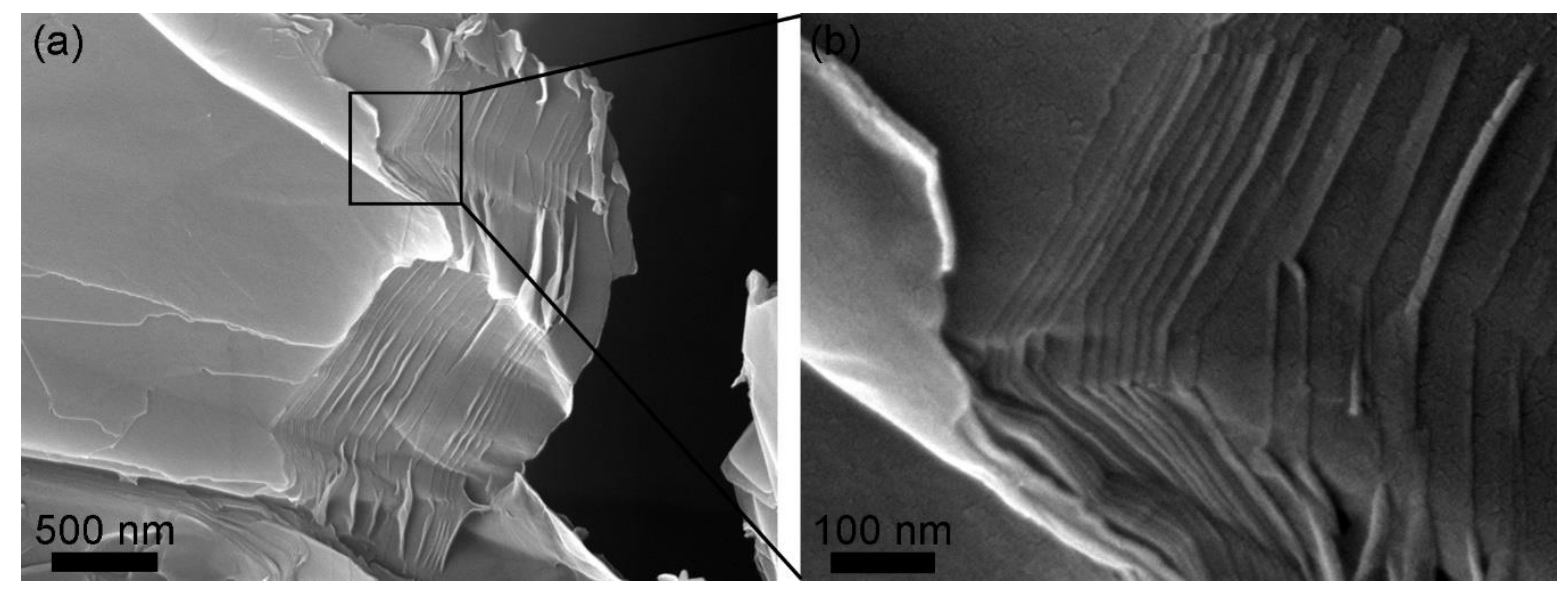

Fig. 5. SEM images collected from H-GO/TKAm sample grain (a) and regions of the grain edges (b).
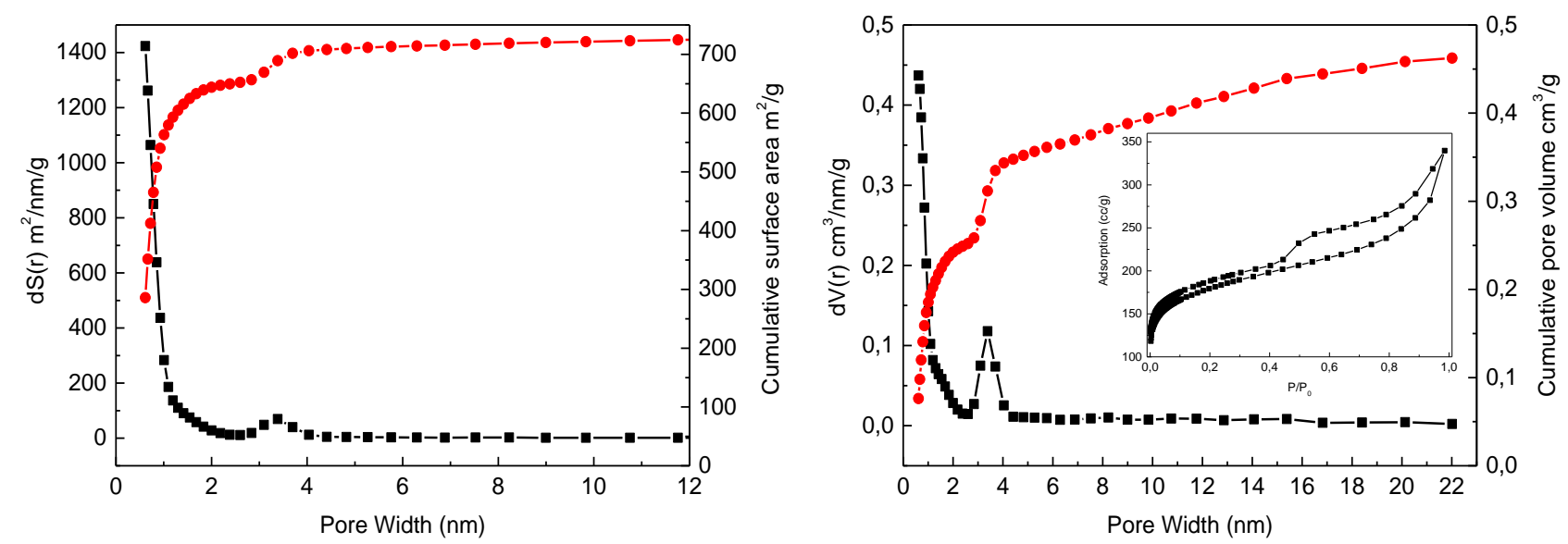

Fig. 6. Nitrogen sorption data for sample of GO/TKAm with highest BET surface area (660 $\mathrm{m}^{2} / \mathrm{g}$ ). Pore size distribution, cumulative surface area and cumulative pore volume calculated using QSDFT model. Inset shows pristine isotherm. Sample was vacuum degassed at $120^{\circ} \mathrm{C}$. 
Theoretical modelling presented for GO/TKAm structure in Fig. 1 suggest the presence of 7-8 $\AA$ size slit pores. Therefore, it is interesting to analyze nitrogen sorption isotherms recorded from experimentally prepared samples on the subject of pore size distribution. Indeed, Fig. 6 shows that GO/TKAm with highest BET surface area of $660 \mathrm{~m}^{2} / \mathrm{g}$ (GO:TKAm of 0.5 , prepared at $110^{\circ} \mathrm{C}$ ) exhibits sub-nanometer pores and surface area originates mostly from nanopores with size below $2 \mathrm{~nm}$. Note also that cumulative surface area calculated using QSDFT $\left(725 \mathrm{~m}^{2} / \mathrm{g}\right)$ slightly exceeds BET surface area.
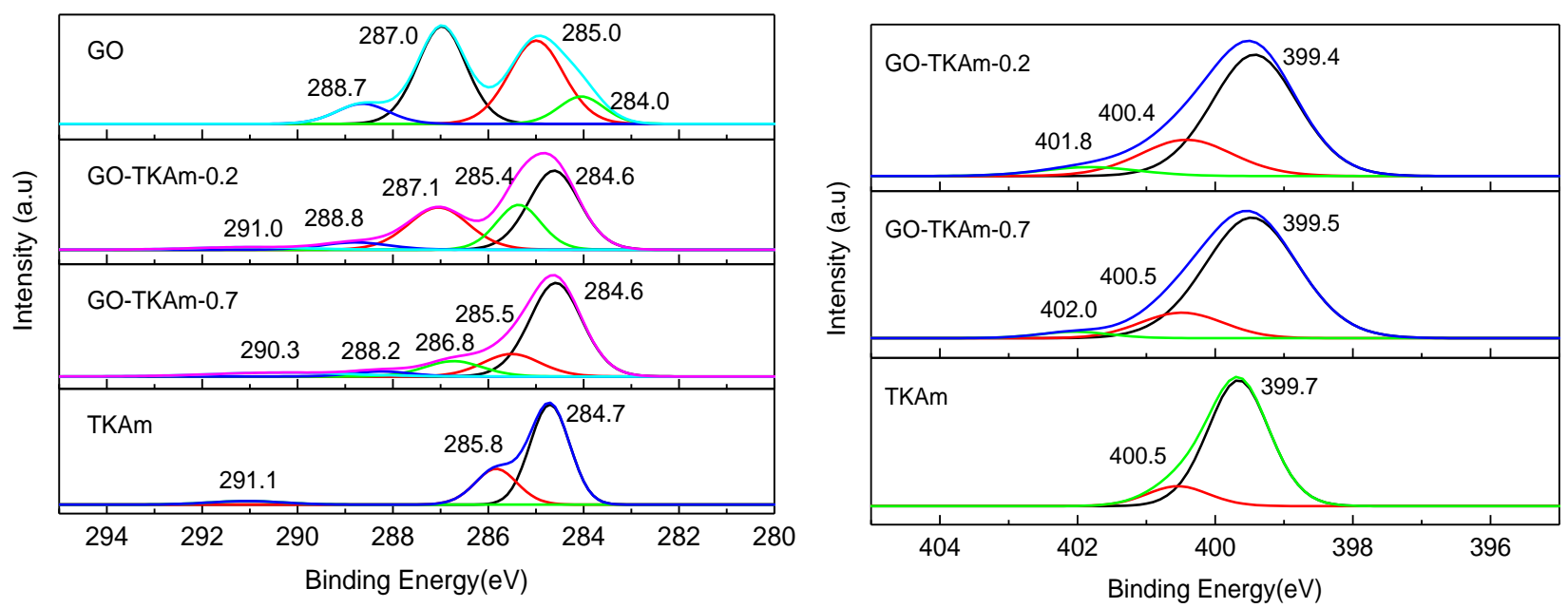

Fig. 7. XPS spectra recorded from precursors GO and TKAm; GO/TKAm materials with loading GO:TKAm ratios of 0.5 and 1.7 ( SSA values of $620 \mathrm{~m}^{2} / \mathrm{g}$ and $246 \mathrm{~m}^{2} / \mathrm{g}$ respectively) for spectral regions of region of $\mathrm{C} 1 \mathrm{~s}$ and $\mathrm{N} 1 \mathrm{~s}$.

The chemical composition of GO pillared with TKAm was verified using XPS (Fig. 7). We assume that intercalation of TKAm into the GO lattice occurs by reaction with epoxy groups keeping the same number of carbon and nitrogen atoms in the pillaring unit as in the precursor molecule independently on the number of amino groups reacted. Thefore, using atomic concentration of nitrogen in GO/TKAm found by XPS it is possible to estimate density of pillaring units. One molecule of TKAm per 41.6 carbon atoms of GO lattice was found to be intercalated for the sample with initial ratio of precursor GO:TKAm of 0.5 and one molecule per 20.8 carbon atoms forthe sample with GO:TKAm ratio of 1.7. It is also possible to estimate $\mathrm{C} / \mathrm{O}$ ratio for $\mathrm{GO}$ sheets after insertion of pillars by assuming $\mathrm{N}: \mathrm{C}=1: 6.25$ for pillaring units according to the formula of TKAm $\left(\mathrm{C}_{25} \mathrm{~N}_{4} \mathrm{H}_{24}\right)$. This estimation yeilded values of $\mathrm{C} / \mathrm{O}=3.3$ and 
$\mathrm{C} / \mathrm{O}=2.6$ for samples with initial GO: TKAm ratios of 0.7 and 0.2 respectively compared to precursor $\mathrm{GO} \mathrm{C} / \mathrm{O}=2.5$. Therefore, the sample with higher density of TKAm pillars is partly reduced compared to precursor GO. However, the sample with maximal SSA shows almost the same $\mathrm{C} / \mathrm{O}$ ratio as in precursor $\mathrm{GO}$.

Further information about chemical composition and stability of pillared GO/TKAm can be obtained using analysis of TGA data (Fig. 8).

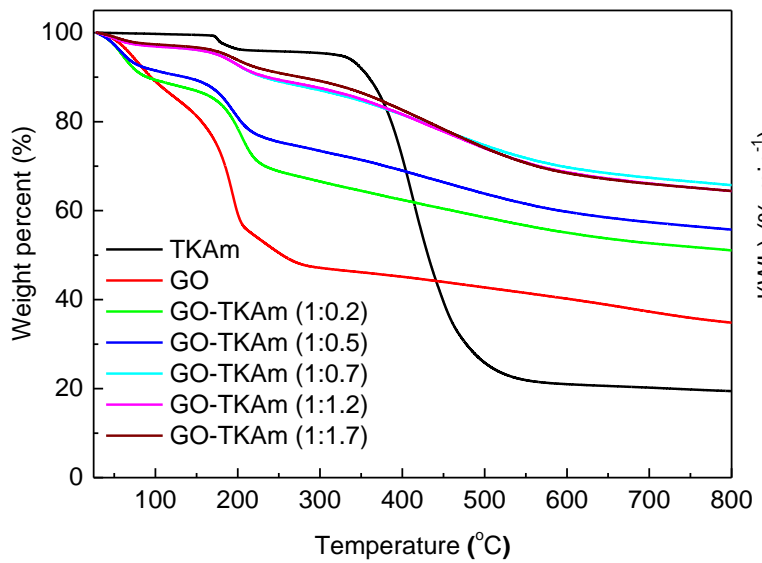

a)

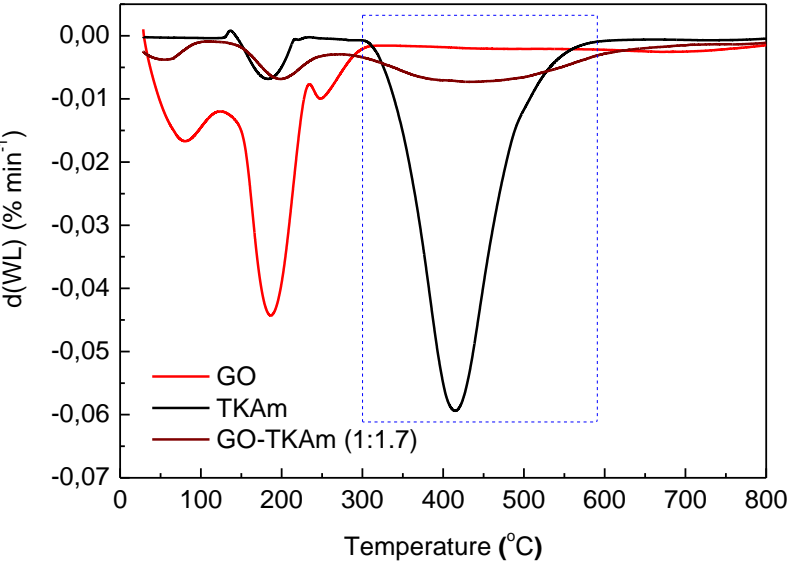

b)

Fig. 8. a) TGA data for samples of HGO/TKAm with different initial weight ratio and TGA traces of precursor HGO and TKAm. b) Derivate plots for TGA traces of reference GO, TKAm and GO-TKAm (1:1.7) sample which illustrates two-step decomposition.

Precursor $\mathrm{H}-\mathrm{GO}$ shows weigth loss due to evaporation of water below $150^{\circ} \mathrm{C}$ and major weight loss step of $\sim 30 \mathrm{wt} \%$ due to decomposition and deflagration in the temperature region $150-250^{\circ} \mathrm{C}$. It is known that thermal decomposition of GO in this temperature range occurs with evaporation of $\mathrm{CO}$ and $\mathrm{CO}_{2}$, not simply oxygen. Precursor TKAm shows major weight loss step of about $75 \mathrm{wt} \%$ at higher temperatures $\left(400-500^{\circ} \mathrm{C}\right)$. Therefore, thermal decomposition of pillared GO/TKAm could be expected to occur in two steps: first one due to decomposition of H-GO and the second one due to degradation of TKAm. Indeed, all experimental TGA traces shown in Fig. 8 for samples with various initial GO:TKAm load show two step decomposition providing evidence for composite GO/TKAm structure. The weigth loss due to decomposition of TKAm is about $13 \mathrm{wt} \%$ for sample with initial load ration GO:TKAm of 0.2 and saturates at 
19-22 wt\% for samples with initial load ratio 0.7-1.7. If we assume that GO/TKAm sample weight loss in TGA corresponds to a simple sum of weight losses due to decompositions of GO and TKAm precursors, it is possible to estimate the sample composition. For the sample with lowest initial ratio (and highest SSA) shown in Fig. 8 this estimation is reasonable since we know from XPS data that $\mathrm{C} / \mathrm{O}$ ratio of GO does not change after solvothermal reaction with TKAm. This sample shows weight loss of $\sim 13 \mathrm{wt} \%$ due to TKAm degradation, while the precursor TKAm shows weight loss of $75 \mathrm{wt} \%$. Simple calculation shows that observed weight loss corresponds to the same composition of GO/TKAm as precursor GO:TKAm ratio of 0.2.

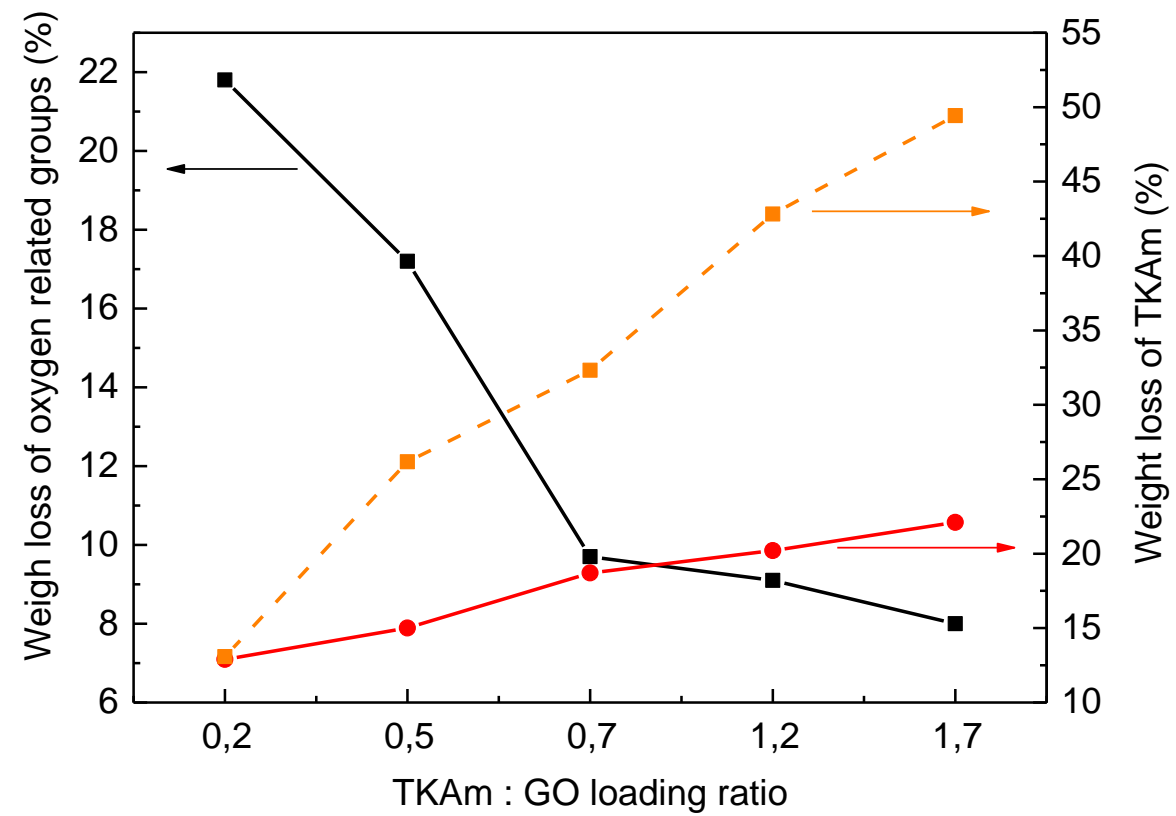

Fig. 9. Weight loss observed for samples with various loading GO:TKAm ratio for temperature regions of GO decomposition (393-573K) (•) and TKAm decomposition (573-923K) (•). Expected weight loss for GO:TKAm with composition identical to the loading ratio is shown as a reference $(\square)$.

Increasing loading TKAm:GO ratio over 0.2 results in higher density of pillaring molecules and partial reduction of GO as evidenced by analysis of TGA data presentedin Fig. 9. It can be concluded that the highest surface area (observed in this set of experiments for GO:TKAm ratio of 0.2 and 0.5 ) is achieved when concentration of pillaring molecules is relatively low and GO is little or not reduced. This conclusion has important implications for analysis of hydrogen sorption isotherms presented below. The graphene sheets remain to be highly oxidized in our 
samples even after pillaring with TKAm units. Therefore, the pillared GO/TKAm material can not be considered as graphene pillared with molecules which has impications for analysis hydrogen sorption data presented below.

It should be noted that attempts to achieve higher surface area by post-synthesis annealing were not successful. Increasing vacuum degassing temperature from $110{ }^{\circ} \mathrm{C}$ to $160^{\circ} \mathrm{C}$ resulted in $20 \%$ drop of SSA value (see Figure S5 in SI).

\subsection{Hydrogen storage properties of pillared GO/TKAm}

Hydrogen sorption was measured for two samples at ambient and liquid nitrogen temperatures (Fig. 10).

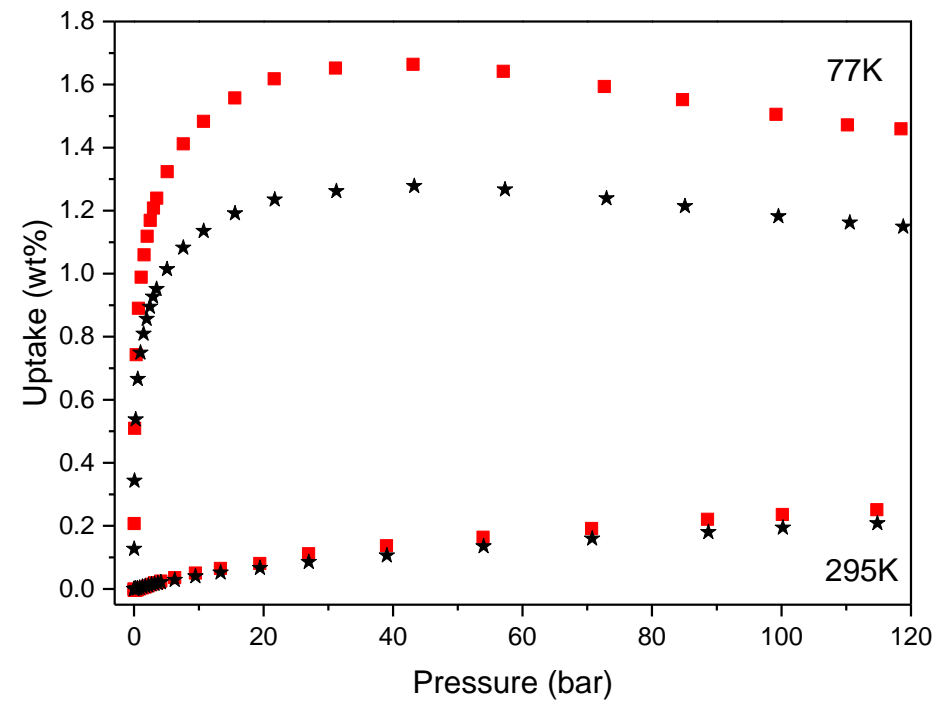

Fig. 10. Hydrogen sorption measured for GO/TKAm using volumetric method: a) isotherms recorded at $295 \mathrm{~K}$ and $77 \mathrm{~K}$ for samples with SSA values of $410 \mathrm{~m}^{2} / \mathrm{g}(\star)$ and $580 \mathrm{~m}^{2} / \mathrm{g} \mathrm{( \varpi )}$ (measured after $\mathrm{H}_{2}$ tests). Samples were degassed at 393K prior to sorption tests. 


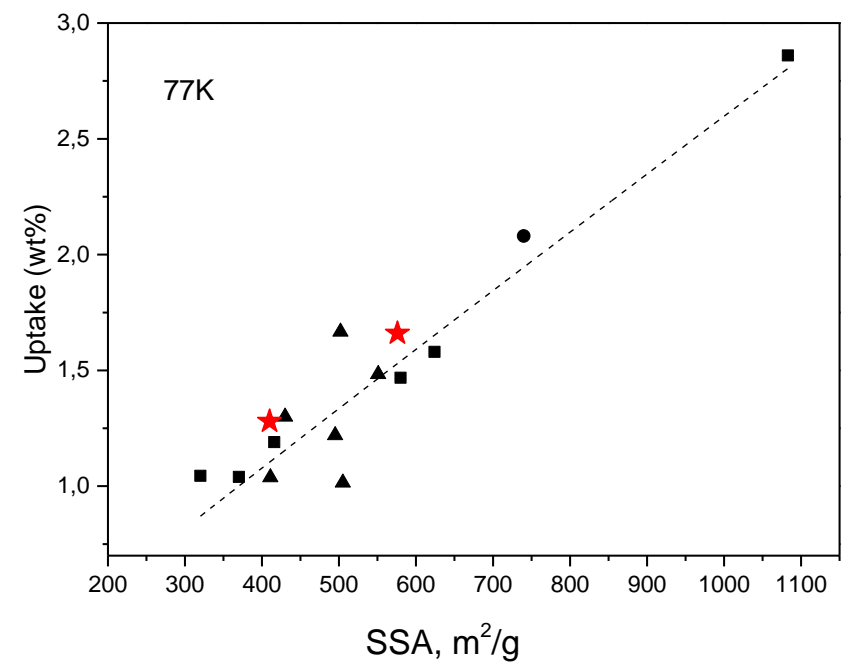

a)

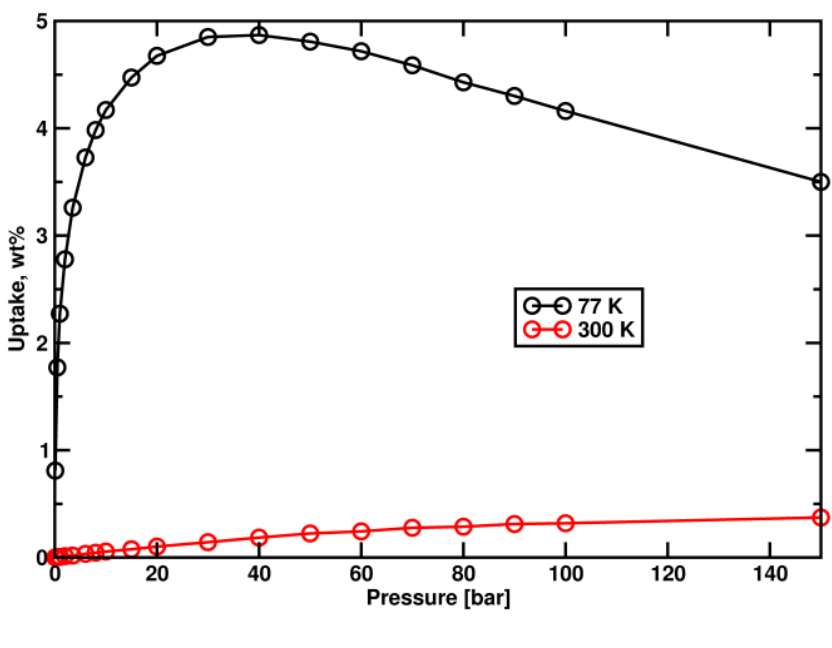

(b)

Fig. 11. (a) hydrogen sorption at 120 bar $\mathrm{H}_{2}$ pressure vs $\mathrm{SSA}$ trend at $77 \mathrm{~K}$ for samples of GO/TKAm ( $\left.{ }^{\star}\right)$ compared to samples of other graphene-related materials: r-GO (घ) [60], pillared GO/DBA ( $\boldsymbol{\Delta}$ ) [24] and mesoporous carbon (•). (b) Simulated hydrogen adsorption isotherms for the model structure shown in Fig. 2a.

The best values of hydrogen sorption $(1.66 \mathrm{wt} \%$ at $77 \mathrm{~K}$ and $0.25 \mathrm{wt} \%$ at $295 \mathrm{~K}$ ) were obtained for sample with initial SSA of $660 \mathrm{~m}^{2} / \mathrm{g}$ measured on as- synthesized sample. Hydrogen sorption was verified for this sample also using gravimetric method which provided at $295 \mathrm{~K}$ value of $0.21 \mathrm{wt} \%$ in good agreement with measurement made volumetric method. It shall be noted that the SSA measured before and after $\mathrm{H}_{2}$ tests with first sample showed about $50 \%$ decrease which was attributed to compaction of sample inside of test cell. Even relatively light pressing of sample resulted in significant reduction of surface area. For second sample the cell was filled with powder without pressing. In this case the SSA measured after $\mathrm{H}_{2}$ test was closer to the precursor value $\left(660 \mathrm{~m}^{2} / \mathrm{g}\right)$ but still showed decrease to $576 \mathrm{~m}^{2} / \mathrm{g}$. Increase of degassing temperature from $393 \mathrm{~K}$ to $413 \mathrm{~K}$ provided $9 \%$ increase in hydrogen sorption at 120 bar and 295 K. Higher temperatures of degassing were not tested due to degradation of material above 413 K.

Hydrogen sorption values measured on pillared GO/TKAm correlate with BET surface area according to standard for all carbon materials trend. The values of SSA recorded after $\mathrm{H}_{2}$ tests 
were used for this estimation. Fig. 11 shows that hydrogen sorption at $77 \mathrm{~K}$ by GO/TKAm samples follows the same trend as other graphene-related materials studied in our previous publications [24, 37, 60], including pillared GO obtained by reaction with DBA. Therefore, it is already verified on two pilared GO materials that hydrogen sorption shows the same correlation with BET SSA as other carbon materials. This result allows to predict hydrogen sorption by GO/TKAm material with SSA values close to theoretical maximum to be about $0.7 \mathrm{wt} \%$ at 120 bar of $\mathrm{H}_{2}$ pressure [61].

This value is also in good agreement with theoretical estimation of hydrogen sorption for the ideal structure with a regular arrangement of pillars (Fig. 2) which amounts to 5 wt\% (saturation value at $77 \mathrm{~K})$ and to $\sim 0.5 \mathrm{wt} \%(300 \mathrm{~K}, 150 \mathrm{bar})$. The uptake measured experimentally at $77 \mathrm{~K}$ is smaller by a factor of 3 in good agreement with the difference in the SSA $\left(2230 \mathrm{~m}^{2} / \mathrm{g}\right.$ in theory vs. $580 \mathrm{~m}^{2} / \mathrm{g}$ in experiment). However, preparation of material with a regular arrangement of pillars is rather challenging due to inhomogenous intercalation of GO discussed above.

\section{Discussion}

Characterization of GO/TKAm sample presented above demonstrated that solvothermal reaction at optimized conditions results in formation of porous of $\mathrm{H}-\mathrm{GO}$ with structure pillared by TKAm molecules and relatively high surface area of about $660 \mathrm{~m}^{2} / \mathrm{g}$. That is one of the highest values ever reported for pillared GO inferior only to recently optimized GO/DBA materials (Table 1).

Table 1. Summary of pillared GO structures reported in literature with data on type of linker molecules used, inter-layer distance (D-spacing), SSA, hydrogen sorption (when available).

\begin{tabular}{|c|c|c|c|c|c|c|}
\hline & $\begin{array}{c}\text { Materials } \\
\text { name }\end{array}$ & Molecules (Linker) & $\begin{array}{c}\text { D- } \\
\text { spacing } \\
(\mathrm{nm})\end{array}$ & $\begin{array}{c}\text { SSA } \\
\left(\mathrm{m}^{2} / \mathrm{g}\right)\end{array}$ & $\begin{array}{c}\text { Hydrogen } \\
\text { storage }\end{array}$ & Ref. \\
\hline 1 & GOF & $\begin{array}{c}\text { Benzene-1,4-diboronic } \\
\text { acid }\end{array}$ & 1.07 & 1030 & $\begin{array}{c}1.7 \mathrm{wt} \% \text { at } 20 \\
\text { bar, 77K }\end{array}$ & {$[24]$} \\
\hline 2 & PGF & 1,4 -diethynylbenzene & 2.1 & 825 & $\begin{array}{c}1.2 \mathrm{wt} \% \text { at } 1 \\
\text { bar, 77K }\end{array}$ & {$[25]$} \\
\hline 3 & GO-TKAm & TKAm & 1.33 & 660 & & $\begin{array}{c}\text { Present } \\
\text { work }\end{array}$ \\
\hline
\end{tabular}




\begin{tabular}{|c|c|c|c|c|c|c|}
\hline 4 & $\begin{array}{l}\mathrm{C}_{8} \mathrm{SiGO}-\mathrm{APS}- \\
\mathrm{Fe}-500\end{array}$ & APS-Fe & 1.48 & 482 & & {$[62]$} \\
\hline 5 & GOF & $\begin{array}{c}\text { Benzene-1,4-diboronic } \\
\text { acid }\end{array}$ & 1.05 & 470 & $\begin{array}{c}1 \mathrm{wt} \% \text { at } 1 \text { bar, } \\
77 \mathrm{~K} \\
1.2 \mathrm{wt} \% \text { at } 10 \\
\text { Bar, } 77 \mathrm{~K}\end{array}$ & $\begin{array}{l}{[23]} \\
{[35]}\end{array}$ \\
\hline 6 & GOF-14PDBA & $\begin{array}{l}\text { 1,4-phenyldiboronic } \\
\text { acid }\end{array}$ & 1 & 470 & $\begin{array}{c}1.1 \mathrm{wt} \% \text { at } 1 \\
\text { bar, } 77 \mathrm{~K}\end{array}$ & {$[35]$} \\
\hline 7 & f-TEG & $\begin{array}{c}4,4^{\prime}- \\
\text { Methylenedianiline }\end{array}$ & & 440 & $\begin{array}{c}1.6 \text { wt } \% \text { at } 2 \\
\text { bar, } 77 \mathrm{~K}\end{array}$ & [63] \\
\hline 8 & $\mathrm{rGO}-\mathrm{BD} 1$ & $\begin{array}{l}\text { Phenylbis-diazonium } \\
\text { salts }\end{array}$ & 0.49 & 438 & & {$[64]$} \\
\hline 9 & Mn-GOF & Mn-TBPP & 2.68 & 259 & & {$[65]$} \\
\hline 10 & G3DCN- & Benzidine & 1.27 & 254 & & {$[66]$} \\
\hline 11 & PGF & 4-iodophenyl & & 242 & & {$[67]$} \\
\hline 12 & 4-MGF(RT) & $\begin{array}{l}\text { Ni(II) macrocyclic } \\
\text { complex }\end{array}$ & 1.4 & 188 & & {$[68]$} \\
\hline 13 & IGOs & Diaminoalkanes & 1.24 & 26 & & [69] \\
\hline 14 & FPGF-200 & Graphene fragments & 3.9 & 7 & & {$[70]$} \\
\hline 15 & GO-PPD/CA & p-phenylenediamine & 1.09 & & & {$[28]$} \\
\hline 16 & GO-DAB $_{16}$ & $\mathrm{DAB}_{16}$ dendrimers & 1.59 & & & [36] \\
\hline
\end{tabular}

Material with next largerst SSA value of $825 \mathrm{~m}^{2} / \mathrm{g}$ included in the Table $\mathbf{1}$ is, in fact, functionalized mesoporous reduced graphene oxide, not PGO material [25]. The contribution of pillaring molecules into the SSA of this material is not clear. Surface area was not reported for several materials included in the Table 1 and according to the definition of pillared material given in this study they should be named as intercalated or functionalized GO until more data on porosity will be available. The finely dispersed and freeze dried GO shows SSA values of tens $\mathrm{m}^{2} / \mathrm{g}$ and even up to $200 \mathrm{~m}^{2} / \mathrm{g}$ according to some reports [66]. Therefore, it can not be excluded that smaller surface areas reported for some of the listed materials might actually be not connected to pillaring of graphene or GO but originate from outer surface of finely dispersed GO flakes. Some of the reactions performed at higher temperatures or under conditions of chemical reduction could also lead to trivial reduction of GO. The chemically reduced GO often exhibits SSA values of up to $300-400 \mathrm{~m}^{2} / \mathrm{g}$ for few layered rGO samples. Therefore, simple detection of SSA values $<200 \mathrm{~m}^{2} / \mathrm{g}$ by analysis of nitrogen sorption and expansion of GO lattice is not yet a decisive evidence for synthesis of pillared structure with $\mathrm{nm}$ size pores provided by inter-layers of GO. Finely dispersed few layered GO with relatively high surface area may also be in intercalated state and exhibit not accessible for gases expanded inter-layer space. 
Therefore, presence of nanopores with diameter which correlates with inter-layer distance must be considered as a crucial evidence for preparation of pillared strutures similar those provided in Fig. 2. Characterization of GO/TKAm materials shown above provides solid evidence of pillared porous struture. Expansion of GO lattice after solvothermal reaction is in agreement with size ot TKAm molecules while porous structure with relatively high surface area and narrow distribution of pores with mostly subnanometer size are confirmed by analysis of nitrogen sorption isotherms. The SSA of GO/TKAm materials correlates with amount of inserted TKAm molecules and increases when density of pillaring molecules is smaller. The swelling properties of GO/TKAm are compatible with the structure shown in Fig. 2a where TKAm molecules are covalently attached only to one side of GO inter-layers. That is similar to previously studied GO/DBA materials which also exhibited increase of inter-layer distance due to swelling in water and alcohols not compatible with covalent bonding of pillaring molecules on both sides of GO inter-layer [24]. The real structure of experimentally prepared GO/TKAm materials is complicated because of inhomogeneous intercalation of pillar molecules. However, the structure shown in Fig. 2 demonstrating an idealized "slit pore" should be considered as a model to estimate an upper bound for SSA. The maximal experimental surface area $\left(660 \mathrm{~m}^{2} / \mathrm{g}\right)$ and pore volume $\left(0.5 \mathrm{~cm}^{3} / \mathrm{g}\right)$ of the synthesized material are found to be significantly lower than those of the model structure (SSA is $2230 \mathrm{~m}^{2} / \mathrm{g}$ and pore volume $\sim 1.0 \mathrm{~cm}^{3} / \mathrm{g}$ ) where GO are separated by the same distance. Hydrogen storage properties of GO/TKAm are found to correlate with surface area according to well established trends valid for physisorption by graphene-related materials [31,53] and by other high surface area materials [64, 65].Theoretical modelling performed in this study predicts hydrogen storage properties of GO/TKAm material which are in good agreement with experimental values relative to surface area. Deviation from standard wt $\%$ vs SSA trend is not expected from theoretical modelling provided here. The hydrogen sorption of PGO materials can possibly be further increased only if materials with higher SSA values are prepared. Theoretical models with realistic density of pillars (Fig. 1) provide maximal surface area of about $2200 \mathrm{~m}^{2} / \mathrm{g}$, much above experimentally observed 660 $\mathrm{m}^{2} / \mathrm{g}$ value. However, if the sorption follows the standard trend, the hydrogen storage of pillared GO will be hardly competitive with compressed hydrogen at ambient temperature unless SSA values above $3000 \mathrm{~m}^{2} / \mathrm{g}$ are achieved. 
As an example, one can estimate hydrogen storage capacity of $0.122 \mathrm{~m}^{3}$ tank (the size of modern Toyota Mirai hydrogen driven car) if compressed gas is used at standard pressure of 100 bar. The hypothetical GO/TKAm material (the structure in Fgure $2 \mathrm{a}$ ) with $\mathrm{SSA}=2230 \mathrm{~m}^{2} / \mathrm{g}$ is expected to adsorb about $0.5 \mathrm{wt} \%$ of hydrogen (excess uptake) at ambient temperature and 100 bar (Fig. 11b). Assuming the density of the adsorbent to be $0.80 \mathrm{~g} / \mathrm{cm}^{3}$ and the pore volume $\mathrm{V}_{\mathrm{P}}=$ $0.90 \mathrm{~cm}^{3} / \mathrm{g}$, the tank can accommodate $\mathrm{m}=97.6 \mathrm{~kg}$ of the material and therefore can store about $1.16 \mathrm{~kg}$ of hydrogen compared to $0.96 \mathrm{~kg}$ if the tank is filled with compressed hydrogen at 100 bar. Note that this calculation assumes the real density of the material to be equal to the bulk density which is never the case in practice. This simple calculation illustrates that hydrogen storage application requires PGO materials with even smaller size of pores to achieve higher real density and at the same time surface areas significantly exceeding $3000 \mathrm{~m}^{2} / \mathrm{g}$. That is most likely a controversial requirement (high surface areas $>3000 \mathrm{~m}^{2} / \mathrm{g}$ are common for materials with low densities of $c a .0 .5 \mathrm{~g} / \mathrm{cm}^{3}$ ). Therefore, realistic PGO materials with higher SSA will not necessarily be of advantage for hydrogen storage if only physisorption is considered. Below we give an example of pillared structure which has a very high surface area but nevertheless does not provide advantages for hydrogen storage applications.

One possible way to increase SSA over the "graphene limit" was pointed out in our earlier study.[54] Modelling presented in that work showed that 3D assemblies composed of perforated graphene sheets are capable to achieve exceptionally high SSA over $4000 \mathrm{~m}^{2} / \mathrm{g}$. Following a similar approach we built up a structural model based on diboronic acid pillars and perforated graphene assembled from polymerized coronene molecules (Fig. 12). This model structure is characterized by the inter-layer distance of $10.8 \AA$, the surface area of $3700 \mathrm{~m}^{2} / \mathrm{g}$, while the pore volume is $1.30 \mathrm{~cm}^{3} / \mathrm{g}$ (the density is $0.53 \mathrm{~g} / \mathrm{cm}^{3}$ ). Due to very high surface area this structure might look attractive for hydrogen storage but a simple esimation shows the opposite. If the tank with the volume of $0.122 \mathrm{~m}^{3}$ is completely filled with the material shown in Fig. 12, the hydrogen storage capacity of the tank will amount to $1.035 \mathrm{~kg}$ (the mass of the material is 64.66 $\mathrm{kg}$, with the excess uptake of $0.6 \mathrm{wt} \%$ ) yielding a very minor improvement compared to compressed hydrogen at 100 bar and ambient temperature $(0.96 \mathrm{~kg})$. Note that the amount of hydrogen stored in the tank filled by the material shown in Fig. 12 (SSA of $3700 \mathrm{~m}^{2} / \mathrm{g}$ ) will be smaller than the amount stored by the idealized GO/TKAm structure with SSA of $2230 \mathrm{~m}^{2} / \mathrm{g}$. The structure shown in Fig. 12 has higher hydrogen sorption in terms of wt\% $(0.6 \mathrm{wt} \%$ vs. 
$0.5 \mathrm{wt} \%)$, but due to lower real density the amount of the material which can be placed inside the storage tank decreases by $\sim 30 \%$. As a result, the contribution of the material to total storage capacity is not sufficient to demonstrate preferences of adsorptive storage vs. gas compression. This example also demonstrates that the low real density of the material is an essential disadvantage for hydrogen storage despite high surface area, unless the low density is compensated by a very high sorption capacity that is difficult to expect in practice. It is unlikely that surface area of PGO materials can be increased significantly without a corresponding drop in the real density. Low real density of materials with exceptionally high surface area appears to be a major factor limiting the storage performance of PGO materials.

Further improvement of hydrogen storage capacity beyond the standard physisorption trends is required for practical applications of PGO materials. This can possibly be achieved by using chemical modification of GRM's or decoration with certain metal atoms.
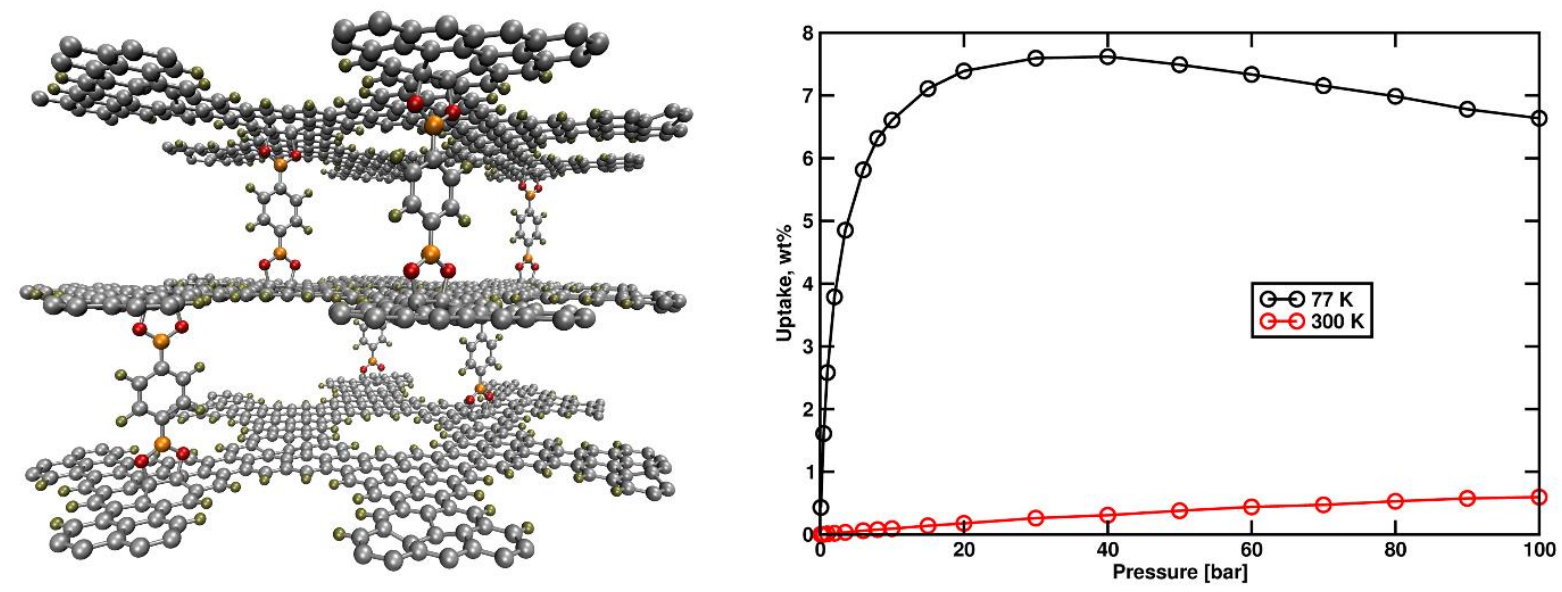

Fig. 12. A structural model of pillared perforated GO with surface area of $3700 \mathrm{~m}^{2} / \mathrm{g}$ and simulated hydrogen adsorption isotherms.

\section{Conclusions}

GO materials pillared with TKAm molecules were prepared and characterized. Optimisation of synthesis procedure allowed to achieve maximum $660 \mathrm{~m}^{2} / \mathrm{g}$ SSA for the structure with inter-layer distance of $\sim 13-14 \AA$ determined by XRD and subnanometer pore size detected using analysis of nitrogen sorption isotherms. The surface area of prepared materials is among highest reported for molecular-pillared GO but not sufficient for hydrogen storage 
applications. The $\mathrm{H}_{2}$ sorption by GO/TKAm is found to follow standard correlation with SSA. Both experimental and theoretical studies presented here reveal correlation of hydrogen uptake with SSA. Furthermore, subnanometer-sized slit pores do not contribute to the increase of uptake beyond well-established trends for microporous materials. However, pillared GO materials presented here can possibly be tested for other applications (e.g. for membrane applications or as molecular sieves) thanks to relatively high surface area, precisely defined distance between GO layers and subnanometer size of slit pores.

\section{Acknowledgements}

Authors akcnowledge support from the Graphene Flagship (contract no. NECT-ICT604391).

A.T. acknowledge the facilities and technical assistance of Cheng C. N. at the Umea Core Facility Electron Microscopy (UCEM) at the Chemical Biological Centre (KBC), Vibrational Spectroscopy Platform Umeå University and A.Shchukarev for assistance with XPS spectra. A.T. also acknowledges financial support from Carl Tryggers Stiftelse.

Istituto Italiano di Tecnologia (IIT) is greatly acknowledged for research funding. The authors A.T.and S.G. wish to thank the COST Action CA 15107 "Multi-Functional Nano-Carbon Composite Materials Network (MultiComp)".

\section{References}

[1] D.A. Dikin, S. Stankovich, E.J. Zimney, R.D. Piner, G.H.B. Dommett, G. Evmenenko, S.T. Nguyen, R.S. Ruoff, Preparation and characterization of graphene oxide paper, Nature 448(7152) (2007) 457-460.

[2] H.P. Boehm, A. Clauss, U. Hofmann, Graphite Oxide and Its Membrane Properties, Journal De Chimie Physique Et De Physico-Chimie Biologique 58(1) (1961) 141-147.

[3] C.M. Chen, Q.H. Yang, Y.G. Yang, W. Lv, Y.F. Wen, P.X. Hou, M.Z. Wang, H.M. Cheng, Self-Assembled Free-Standing Graphite Oxide Membrane, Advanced Materials 21(29) (2009) 3007-3011.

[4] Z.T. Luo, Y. Lu, L.A. Somers, A.T.C. Johnson, High Yield Preparation of Macroscopic Graphene Oxide Membranes, Journal of the American Chemical Society 131(3) (2009) 898-899. [5] H.W. Kim, H.W. Yoon, S.-M. Yoon, A. B.K., C. Y.H., H.J. Shin, H. Yang, U. Paik, S. Kwon, J.-Y. Choi, H.B. Park, Slective gas transport trough few-layered graphene and graphene oxide membranes, Science 342(6154) (2013) 91-95. 
[6] H. Li, Z. Song, X. Zhang, Y. Huang, S. Li, Y. Mao, H.J. Ploehn, Y. Bao, M. Yu, Ultrathin, Molecular-Sieving Graphene Oxide Membranes for Selective Hydrogen Separation Science 342(6154) (2013) 95-98.

[7] Y.P. Tang, D.R. Paul, T.S. Chung, Free-standing graphene oxide thin films assembled by a pressurized ultrafiltration method for dehydration of ethanol, Journal of Membrane Science 458 (2014) 199-208.

[8] A.V. Talyzin, T. Hausmaninger, S.J. You, T. Szabo, The structure of graphene oxide membranes in liquid water, ethanol and water-ethanol mixtures, Nanoscale 6(1) (2014) 272-281.

[9] P.Z. Sun, M. Zhu, K.L. Wang, M.L. Zhong, J.Q. Wei, D.H. Wu, Z.P. Xu, H.W. Zhu, Selective Ion Penetration of Graphene Oxide Membranes, Acs Nano 7(1) (2013) 428-437.

[10] R.K. Joshi, P. Carbone, F.C. Wang, V.G. Kravets, Y. Su, I.V. Grigorieva, H.A. Wu, A.K. Geim, R.R. Nair, Precise and Ultrafast Molecular Sieving Through Graphene Oxide Membranes, Science 343(6172) (2014) 752-754

[11] E.S. Bober, L.C. Flowers, P.K. Lee, D.E. Sestrich, C.-M. Wong, W. Gillam Sherman, S. Johnson, R.H. Horowitz, Final report on Reverse osmosis membranes Containing Graphitic Oxide, Research and development progress report No.544, US Department of the Interior, reprints from the colelction of the University of Michigan Library (1970) 1-113.

[12] A. Nicolai, B.G. Sumpter, V. Meuniera, Tunable water desalination across graphene oxide framework membranes, Phys Chem Chem Phys 16(18) (2014) 8646-8654.

[13] B.C. Brodie, On the Atomic Weight of Graphite, Philosophical Transactions of the Royal Society of London 149 (1859) 249-259.

[14] U. Hofmann, A. Frenzel, E. Csalán, Die Konstitution der Graphitsäure und ihre Reaktionen, Justus Liebigs Annalen der Chemie 510(1) (1934) 1-41.

[15] F.A. Delacruz, D.M.C. Macewan, Sorption of Organic Molecules by Graphitic Acid and Methylated Graphitic Acid - a Preliminary Study, Kolloid Z Z Polym 203(1) (1965) 36-\&.

[16] J.C. Ruiz, D.M.C. Macewan, Interlamellar Sorption Complexes of Graphitic Acid with Organic Substances, Nature 176(4495) (1955) 1222-1223.

[17] A.V. Talyzin, B. Sundqvist, T. Szabo, I. Dekany, V. Dmitriev, Pressure-Induced Insertion of Liquid Alcohols into Graphite Oxide Structure, Journal of the American Chemical Society 131(51) (2009) 18445-18449.

[18] W.S. Hummers, R.E. Offeman, Preparation of Graphitic Oxide, J Am Chem Soc 80(6) (1958) 1339-1339.

[19] S.J. You, S. Luzan, J.C. Yu, B. Sundqvist, A.V. Talyzin, Phase Transitions in Graphite Oxide Solvates at Temperatures Near Ambient, Journal of Physical Chemistry Letters 3(7) (2012) 812-817.

[20] S.J. You, J.C. Yu, B. Sundqvist, A.V. Talyzin, Solvation of graphite oxide in watermethanol binary polar solvents, Phys Status Solidi B 249(12) (2012) 2568-2571.

[21] S.J. You, B. Sundqvist, A.V. Talyzin, Enormous Lattice Expansion of Hummers Graphite Oxide in Alcohols at Low Temperatures, Acs Nano 7(2) (2013) 1395-1399.

[22] S.J. You, J.C. Yu, B. Sundqvist, L.A. Belyaeva, N.V. Avramenko, M.V. Korobov, A.V. Talyzin, Selective Intercalation of Graphite Oxide by Methanol in Water/Methanol Mixtures, J Phys Chem C 117(4) (2013) 1963-1968.

[23] J.W. Burress, S. Gadipelli, J. Ford, J.M. Simmons, W. Zhou, T. Yildirim, Graphene Oxide Framework Materials: Theoretical Predictions and Experimental Results, Angewandte ChemieInternational Edition 49(47) (2010) 8902-8904. 
[24] G. Mercier, A. Klechikov, M. Hedenstrom, D. Johnels, I.A. Baburin, G. Seifert, R. Mysyk, A.V. Talyzin, Porous Graphene Oxide/Diboronic Acid Materials: Structure and Hydrogen Sorption, J Phys Chem C 119(49) (2015) 27179-27191.

[25] R. Kumar, V.M. Suresh, T.K. Maji, C.N.R. Rao, Porous graphene frameworks pillared by organic linkers with tunable surface area and gas storage properties, Chemical Communications 50(16) (2014) 2015-2017.

[26] E. Quesnel, F. Roux, F. Emieux, P. Faucherand, E. Kymakis, G. Volonakis, F. Giustino, B. Martin-Garcia, I. Moreels, S.A. Gursel, A.B. Yurtcan, V. Di Noto, A. Talyzin, I. Baburin, D. Tranca, G. Seifert, L. Crema, G. Speranza, V. Tozzini, P. Bondavalli, G. Pognon, C. Botas, D. Carriazo, G. Singh, T. Rojo, G. Kim, W.J. Yu, C.P. Grey, V. Pellegrini, Graphene-based technologies for energy applications, challenges and perspectives, 2d Mater 2(3) (2015).

[27] L. Li, J.J. Qiu, S.R. Wang, Polyaniline Nanowire-Pillared Graphene for Supercapacitor Electrode, Soft Mater 11(4) (2013) 503-509.

[28] W.S. Hung, C.H. Tsou, M. De Guzman, Q.F. An, Y.L. Liu, Y.M. Zhang, C.C. Hu, K.R. Lee, J.Y. Lai, Cross-Linking with Diamine Monomers To Prepare Composite Graphene OxideFramework Membranes with Varying d-Spacing, Chem Mater 26(9) (2014) 2983-2990.

[29] S. Patchkovskii, J.S. Tse, S.N. Yurchenko, L. Zhechkov, T. Heine, G. Seifert, Graphene nanostructures as tunable storage media for molecular hydrogen, Proceedings of the National Academy of Sciences of the United States of America 102(30) (2005) 10439-10444.

[30] M. Rzepka, P. Lamp, M.A. de la Casa-Lillo, Physisorption of hydrogen on microporous carbon and carbon nanotubes, J Phys Chem B 102(52) (1998) 10894-10898.

[31] Y. Matsuo, S. Ueda, K. Konishi, J.P. Marco-Lozar, D. Lozano-Castello, D. CazorlaAmoros, Pillared carbons consisting of silsesquioxane bridged graphene layers for hydrogen storage materials, Int J Hydrogen Energ 37(14) (2012) 10702-10708.

[32] Y. Matsuo, Y. Sakai, T. Fukutsuka, Y. Sugie, Preparation of pillared carbons by pyrolysis of silylated graphite oxide, Chem Lett 36(8) (2007) 1050-1051.

[33] Y. Matsuo, K. Konishi, Intercalation of various organic molecules into pillared carbon, Carbon 50(6) (2012) 2280-2286.

[34] F. Guo, M. Creighton, Y.T. Chen, R. Hurt, I. Kulaots, Porous structures in stacked, crumpled and pillared graphene-based 3D materials, Carbon 66 (2014) 476-484.

[35] G. Srinivas, J.W. Burress, J. Ford, T. Yildirim, Porous graphene oxide frameworks: Synthesis and gas sorption properties, J Mater Chem 21(30) (2011) 11323-11329.

[36] T. Tsoufis, F. Katsaros, Z. Sideratou, G. Romanos, O. Ivashenko, P. Rudolf, B.J. Kooi, S. Papageorgiou, M.A. Karakassides, Tailor-made graphite oxide-DAB poly(propylene imine) dendrimer intercalated hybrids and their potential for efficient $\mathrm{CO} 2$ adsorption, Chem Commun 50(75) (2014) 10967-10970.

[37] A. Klechikov, G. Mercier, T. Sharifi, I.A. Baburin, G. Seifert, A.V. Talyzin, Hydrogen storage in high surface area graphene scaffolds, Chem Commun 51(83) (2015) 15280-15283.

[38] R. Grunker, V. Bon, P. Muller, U. Stoeck, S. Krause, U. Mueller, I. Senkovska, S. Kaskel, A new metal-organic framework with ultra-high surface area, Chem Commun 50(26) (2014) 3450-3452.

[39] A.B. Bourlinos, D. Gournis, D. Petridis, T. Szabo, A. Szeri, I. Dekany, Graphite oxide: Chemical reduction to graphite and surface modification with primary aliphatic amines and amino acids, Langmuir 19(15) (2003) 6050-6055. 
[40] Y. Matsuo, S. Higashika, K. Kimura, Y. Miyamoto, T. Fukutsuka, Y. Sugie, Synthesis of polyaniline-intercalated layered materials via exchange reaction, J Mater Chem 12(5) (2002) 1592-1596.

[41] A. Lerf, H.Y. He, M. Forster, J. Klinowski, Structure of graphite oxide revisited, Journal of Physical Chemistry B 102(23) (1998) 4477-4482.

[42] Y. Matsuo, T. Miyabe, T. Fukutsuka, Y. Sugie, Preparation and characterization of alkylamine-intercalated graphite oxides, Carbon 45(5) (2007) 1005-1012.

[43] A. Gupta, S.K. Saha, Photoluminescence Study in Diaminobenzene Functionalized Graphene Oxide, Aip Conf Proc 1620 (2014) 10-14.

[44] A. Gupta, B.K. Shaw, S.K. Saha, Photoluminescence study of optically active diaminopyridine intercalated graphene oxide, Rsc Adv 4(92) (2014) 50542-50548.

[45] K. Spyrou, G. Potsi, E.K. Diamanti, X.X. Ke, E. Serestatidou, I.I. Verginadis, A.P. Velalopoulou, A.M. Evangelou, Y. Deligiannakis, G. Van Tendeloo, D. Gournis, P. Rudolf, Towards Novel Multifunctional Pillared Nanostructures: Effective Intercalation of Adamantylamine in Graphene Oxide and Smectite Clays, Adv Funct Mater 24(37) (2014) 58415850 .

[46] P. Ganesan, X.N. Yang, J. Loos, T.J. Savenije, R.D. Abellon, H. Zuilhof, E.J.R. Sudholter, Tetrahedral n-type materials: Efficient quenching of the excitation of p-type polymers in amorphous films, J Am Chem Soc 127(42) (2005) 14530-14531.

[47] B.C. Brodie, Ann. Chim Phys. 59 (1860).

[48] S.J. You, S.M. Luzan, T. Szabo, A.V. Talyzin, Effect of synthesis method on solvation and exfoliation of graphite oxide, Carbon 52 (2013) 171-180.

[49] J. Rouquerol, P. Llewellyn, F. Rouquerol, Is the BET equation applicable to microporous adsorbents?, Characterization of Porous Solids Vii - Proceedings of the 7th International Symposium on the Characterization of Porous Solids (Cops-Vii), Aix-En-Provence, France, 2628 May 2005160 (2006) 49-56.

[50] A.V. Talyzin, A. Jacob, Hydrogen adsorption by ball milled C-60, Journal of Alloys and Compounds 395(1-2) (2005) 154-158.

[51] G. De Weireld, M. Frere, R. Jadot, Automated determination of high-temperature and highpressure gas adsorption isotherms using a magnetic suspension balance, Measurement Science \& Technology 10(2) (1999) 117-126.

[52] M.D. Dolan, K.G. McLennan, D. Chandra, M.A. Kochanek, G. Song, Suppression of the critical temperature in binary vanadium hydrides, J Alloy Compd 586 (2014) 385-391.

[53] J. Srenscek-Nazzal, W. Kaminska, B. Michalkiewicz, Z.C. Koren, Production, characterization and methane storage potential of $\mathrm{KOH}$-activated carbon from sugarcane molasses, Industrial Crops and Products 47 (2013) 153-159.

[54] I.A. Baburin, A. Klechikou, G. Mercier, A. Talyzin, G. Seifert, Hydrogen adsorption by perforated graphene, Int J Hydrogen Energ 40(20) (2015) 6594-6599.

[55] G. Seifert, D. Porezag, T. Frauenheim, Calculations of molecules, clusters, and solids with a simplified LCAO-DFT-LDA scheme, Int J Quantum Chem 58(2) (1996) 185-192.

[56] R.R. Nair, H.A. Wu, P.N. Jayaram, I.V. Grigorieva, A.K. Geim, Unimpeded Permeation of Water Through Helium-Leak-Tight Graphene-Based Membranes, Science 335(6067) (2012) 442-444.

[57] Y.B. Zhang, J. Su, H. Furukawa, Y.F. Yun, F. Gandara, A. Duong, X.D. Zou, O.M. Yaghi, Single-Crystal Structure of a Covalent Organic Framework, J Am Chem Soc 135(44) (2013) 16336-16339. 
[58] F.J. Uribe-Romo, J.R. Hunt, H. Furukawa, C. Klock, M. O'Keeffe, O.M. Yaghi, A Crystalline Imine-Linked 3-D Porous Covalent Organic Framework, J Am Chem Soc 131(13) (2009) 4570-+.

[59] B. Rezania, N. Severin, A.V. Talyzin, J.P. Rabe, Hydration of Bilayered Graphene Oxide, Nano Lett 14(7) (2014) 3993-3998.

[60] A.G. Klechikov, G. Mercier, P. Merino, S. Blanco, C. Merino, A.V. Talyzin, Hydrogen storage in bulk graphene-related materials, Micropor Mesopor Mat 210 (2015) 46-51.

[61] A. Klechikov, G. Mercier, J. Yu, A.V. Talyzin, Hydrogen storage in bulk graphene-related materials., Microporous and Mesoporous Materials 210 (2015) 46-51.

[62] J. Maruyama, S. Akita, Y. Matsuo, Y. Muramatsu, Silica-pillared graphene sheets with ironnitrogen units as an oxygen reduction catalyst, Carbon 66 (2014) 327-333.

[63] Z. Jin, W. Lu, K.J. O'Neill, P.A. Parilla, L.J. Simpson, C. Kittrell, J.M. Tour, NanoEngineered Spacing in Graphene Sheets for Hydrogen Storage, Chem. Mater. 23(4) (2011) 923925.

[64] K. Lee, Y. Yoon, Y. Cho, S.M. Lee, Y. Shin, H. Lee, H. Lee, Tunable Sub-nanopores of Graphene Flake Interlayers with Conductive Molecular Linkers for Supercapacitors, ACS Nano 10(7) (2016) 6799-6807.

[65] B.W. Yao, C. Li, J. Ma, G.Q. Shi, Porphyrin-based graphene oxide frameworks with ultralarge d-spacings for the electrocatalyzation of oxygen reduction reaction, PCCP 17(29) (2015) 19538-19545.

[66] X.Y. Zhang, A. Ciesielski, F. Richard, P.K. Chen, E.A. Prasetyanto, L. De Cola, P. Samori, Modular Graphene-Based 3D Covalent Networks: Functional Architectures for Energy Applications, Small 12(8) (2016) 1044-1052.

[67] K. Yuan, Y.Z. Xu, J. Uihlein, G. Brunklaus, L. Shi, R. Heiderhoff, M.M. Que, M. Forster, T. Chasse, T. Pichler, T. Riedl, Y.W. Chen, U. Scherf, Straightforward Generation of Pillared, Microporous Graphene Frameworks for Use in Supercapacitors, Adv. Mater. 27(42) (2015) 6714-6721.

[68] T.K. Kim, J.Y. Cheon, K. Yoo, J.W. Kim, S.M. Hyun, H.S. Shin, S.H. Joo, H.R. Moon, Three-dimensional pillared metallomacrocycle-graphene frameworks with tunable micro- and mesoporosity, J. Mater. Chem. A 1(29) (2013) 8432-8437.

[69] J. Xu, W. Xing, L.M. Zhao, F.F. Guo, X.Z. Wu, W.B. Xu, Z.F. Yan, The CO2 Storage Capacity of the Intercalated Diaminoalkane Graphene Oxides: A Combination of Experimental and Simulation Studies, Nanoscale Res. Lett. 10 (2015) 318.

[70] L.L. Jiang, L.Z. Sheng, C.L. Long, T. Wei, Z.J. Fan, Functional Pillared Graphene Frameworks for Ultrahigh Volumetric Performance Supercapacitors, Adv. Ener. Mater. 5(15) (2015) 1500771. 